\title{
Identification of Sequence Motifs That Target Neuronal Nicotinic Receptors to Dendrites and Axons
}

\author{
Jian Xu, Yongling Zhu, and Stephen F. Heinemann \\ Molecular Neurobiology Laboratory, The Salk Institute, La Jolla, California 92037
}

\begin{abstract}
Neuronal nicotinic acetylcholine receptors (nAChRs) belong to a family of ligand-gated ion channels that play important roles in central and peripheral nervous systems. The subcellular distribution of neuronal nAChRs has important implications for function and is not well understood. Here, we analyzed the targeting of two major types of neuronal nAChRs by expressing epitope-tagged subunits in cultured hippocampal neurons. Surprisingly, the $\alpha 7 \mathrm{nAChR}(\alpha 7)$ and $\alpha 4 / \beta 2 \mathrm{nAChR}(\alpha 4 \beta 2)$ displayed distinct patterns of expression, with $\alpha 7$ targeted preferentially to the somatodendritic compartments, whereas $\alpha 4 \beta 2$ was localized to both axonal and dendritic domains. When fused to CD4 or IL2RA (interleukin 2 receptor $\alpha$ subunit) proteins, which are normally distributed ubiquitously, the M3-M4 intracellular loop from the $\alpha 7$ subunit promoted dendritic expression, whereas the homologous M3-M4 loop from the $\alpha 4$ subunit led to surface axonal expression. Systemic screening and alanine substitution further identified a 25-residue leucine motif ([DE]XXXL[LI]) containing an axonal targeting sequence within the $\alpha 4$ loop and a 48-residue dileucine and tyrosine motif (YXXØ) containing a dendritic targeting sequence from the $\alpha 7$ loop. These results provide valuable information in understanding diverse roles of neuronal nAChRs in mediating and modulating synaptic transmission, synaptic plasticity, and nicotine addiction.
\end{abstract}

Key words: acetylcholine; receptor; dendrite; axon; synapse; nicotine

\section{Introduction}

Nicotinic acetylcholine receptors (nAChRs) are pentameric membrane proteins that form cation-selective ion channels. There are two broad classes of nAChRs based on their general location: muscle nAChRs and neuronal nAChRs. Five genes coding for muscle nAChR subunits $(\alpha, \beta, \delta, \varepsilon$, and $\gamma)$ and 11 genes coding for neuronal nAChRs $(\alpha 2-\alpha 7, \alpha 9-\alpha 10$, and $\beta 2-\beta 4)$ have been identified so far in mammalian organisms (Sargent, 1993; Lukas et al., 1999; Corringer et al., 2000).

Neuronal nAChRs are present on many cells in the central and peripheral nervous systems. These receptors play important physiological roles and have been implicated in disease states such as Alzheimer's disease and nicotine addiction (Dani and Heinemann, 1996; Role and Berg, 1996). Structurally, neuronal $\mathrm{nAChRs}$ are composed of various pentameric combinations of 11 subunits with distinct pharmacological properties and anatomical localizations (Sargent, 1993). At the subcellular level, neuronal nAChRs may be localized in many parts of the cells, including cell bodies, presynaptic terminals, and postsynaptic sites (Role and Berg, 1996; Wonnacott, 1997; Dajas-Bailador and Wonnacott, 2004). Although physiological functions of neuronal

Received Feb. 23, 2006; revised Aug. 8, 2006; accepted Aug. 8, 2006.

This work was supported by National Institutes of Health Grants DA018247, NS028709, and AG010435. J.X. was supported by a National Alliance for Research on Schizophrenia and Depression Young Investigator Award. We thank Dr. Anis Contractor for advice. We also thank Dr. Gary Banker for providing TfR-GFP, Dr. Lily Jan for CD4 construct, Dr. David Bredt for PSD-95-GFP, Dr. John Thomas for Tau-GFP, and Dr. Stefano Vicini for GFP-NR1.

Correspondence should be addressed to Dr. Stephen F. Heinemann, Molecular Neurobiology Laboratory, The Salk Institute, 10010 North Torrey Pines Road, La Jolla, CA 92037. E-mail: heinemann@salk.edu.

D01:10.1523/JNEUROSCI.0840-06.2006

Copyright $\odot 2006$ Society for Neuroscience $\quad$ 0270-6474/06/269780-14\$15.00/0
nAChRs depend critically on their locations in specific regions of the neuron, little is known about the subcellular distribution of neuronal nAChRs, and even less is known about the mechanisms responsible for their assembly and targeting process.

We chose to study neuronal nAChRs containing either the $\alpha 7$ subunit $(\alpha 7)$ or combinations of the $\alpha 4 / \beta 2$ subunits $(\alpha 4 \beta 2)$, because they are the most abundant in the brain and because they participate in important processes, such as synaptic transmission, cognitive function, gene expression, and drug addiction (Dani and Heinemann, 1996). Although the subject has been pursued intensively in the past, the subcellular location of $\alpha 7$ remains elusive and controversial. Electrophysiological and immunochemical evidence supports a mainly presynaptic role and location for $\alpha 7$ at synapses (McGehee et al., 1995; Gray et al., 1996; Fabian-Fine et al., 2001; Jones and Wonnacott, 2004), although other evidence suggests that $\alpha 7$-containing nAChRs are also concentrated to somatodendritic and postsynaptic locations (Alkondon and Albuquerque, 1993; Frazier et al., 1998b; Hefft et al., 1999; Levy and Aoki, 2002; Khiroug et al., 2003). The subcellular distribution of $\alpha 4 \beta 2$ is also poorly understood. According to functional and immunochemical studies, $\alpha 4 \beta 2$ may be present at presynaptic locations (Jones et al., 2001; Zoli et al., 2002; Salminen et al., 2004) and postsynaptic/somatodendritic locations (Alkondon et al., 1999; Arroyo-Jiménez et al., 1999; McQuiston and Madison, 1999; Nashmi et al., 2003). Despite these findings, the question of how $\alpha 4 \beta 2$ receptors are expressed remains unclear. In fact, it is not known whether $\alpha 4 \beta 2$ may coexist in both presynaptic and postsynaptic locations in the same cell.

Studies of the distribution and function of the neuronal $\mathrm{nAChR}$ have been hindered by the lack of subunit-specific antibodies (Herber et al., 2004) and the low expression of endoge- 

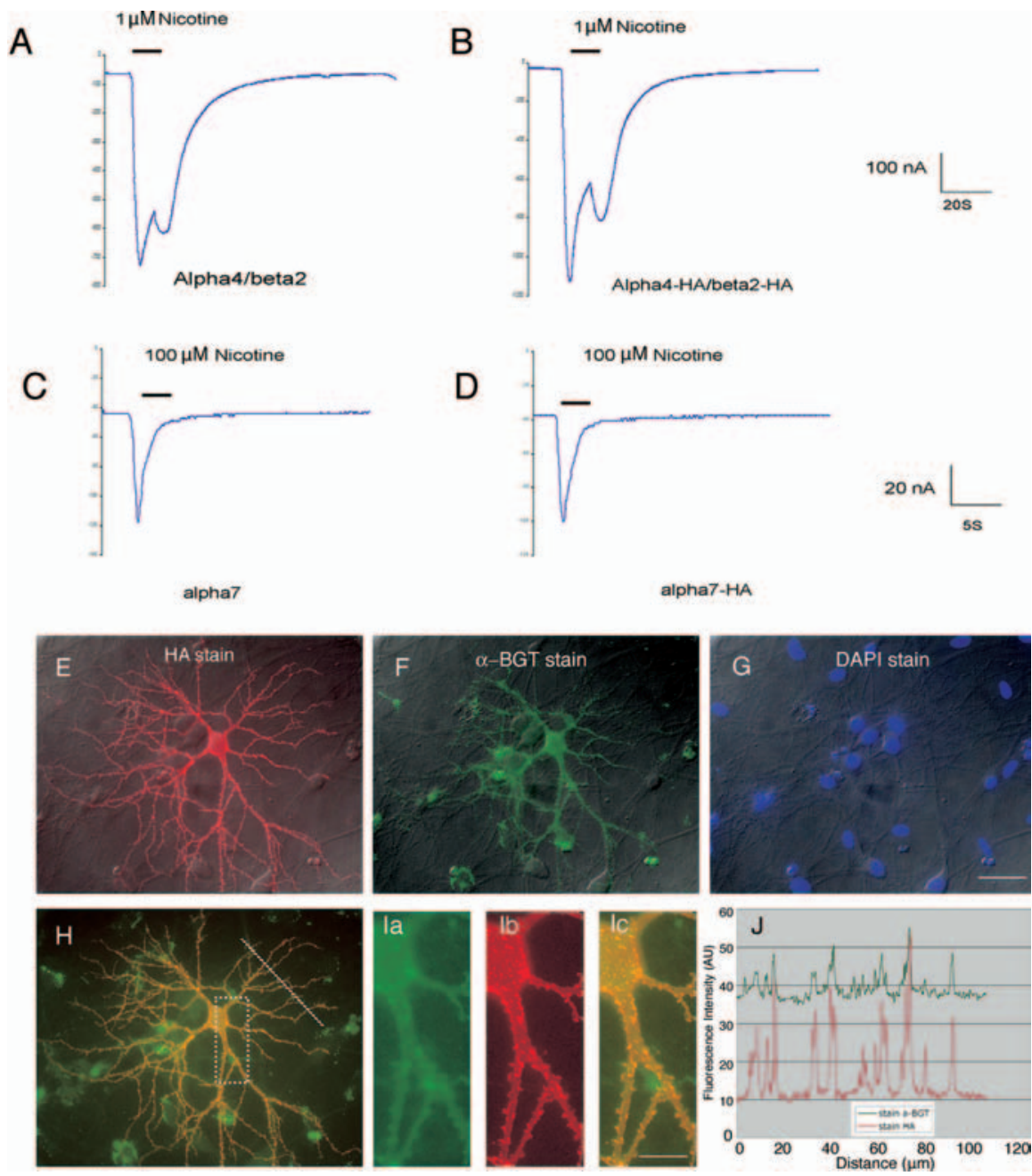

Figure 1. Tagging the receptors at C termini does not affect function and assembling of neuronal nAChRs. $A-D$, Representative examples of nicotine-induced currents from oocytes expressing wild-type $\alpha 4 \beta 2(\boldsymbol{A}), \alpha 4-\mathrm{HA} / \beta 2-\mathrm{HA}(\boldsymbol{B})$, wild-type $\alpha 7(\boldsymbol{C})$, and $\alpha 7-H A(D)$. Voltage clamping was performed $24 \mathrm{~h}$ after injecting RNA into Xenopus 00 cytes. $\boldsymbol{E}-\boldsymbol{J}$, Surface staining of recombinant $\alpha 7$ is consistent with $\alpha$-bungarotoxin labeling. Hippocampal neurons were transfected with $\alpha 7-\mathrm{HA}$ at 8 DIV and stained at 12 DIV. $\boldsymbol{E}$, Surface expression of recombinant $\alpha 7$ stained by HA antibody. $\boldsymbol{F}$, Surface expression of $\alpha 7$ stained by $\alpha$-bungarotoxin (a-BGT). G, Same view as $\boldsymbol{E}$ and $\boldsymbol{F}$. Cell nuclei were labeled with $4^{\prime}, 6^{\prime}$-diamidino-2-phenylindole dihydrochloride (DAPI) to show that one neuron of many from this view was transfected and that the surface expression level of endogenous $\alpha 7$ from nontransfected cells in this view was below detection using fluorescence-labeled $\alpha$-bungarotoxin in our experiments. $\boldsymbol{H}, 0$ verlay of $\boldsymbol{E}$ and $\boldsymbol{F}$ shows the consistent labeling of surface $\alpha 7$ by $\mathrm{HA}$ antibody and $\alpha$-bungarotoxin, except for occasional nonspecific labeling of apparent cell debris by Alexa 488 - $\alpha$-bungarotoxin. $\boldsymbol{I}$, Enlarged boxed region from $\boldsymbol{H}$. Ia, HA stain. Ib, a-BGT stain. $\boldsymbol{I}$, Overlay of $\boldsymbol{I} \boldsymbol{a}$ and $\boldsymbol{I b}$. J, Immunofluorescence intensity profiles along the $100 \mu \mathrm{m}$ line in $\boldsymbol{H}$ were measured from the original TIFF (tagged image file format) images with NIH ImageJ. Scale bars: (in G) $\boldsymbol{E}-\boldsymbol{H}, 50 \mu \mathrm{m} ; \boldsymbol{I}, 15 \mu \mathrm{m}$.

nous receptors in the brain. The complexity of the brain structure further prevents precise mapping of neuronal $\mathrm{nAChRs}$ in a single neuron. To circumvent these problems, we expressed tagged receptors in primary hippocampal cultures. Because neurons in such cultures develop morphological polarity in vitro and because their neurites are arrayed essentially in two dimensions at relatively low densities, compared with the densely packed condition in the brain, hippocampal cultures were widely used for examining polarized expression of neuronal membrane proteins (Craig and Banker, 1994). The presence of at least two subtypes of neuronal nAChRs on hippocampal cultures, as demonstrated by electrophysiological studies (Alkondon and Albuquerque, 1993) and immunohistochemical studies (Zarei et al., 1999; Liu et al., 2001; Kawai et al., 2002), further suggests that these cultures can
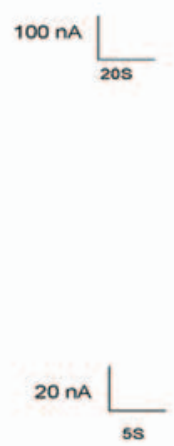

be applied to identify conditions that control the distribution of nAChRs within neurons. In this study, we demonstrate that neuronal nAChRs composed of different subunits are expressed with distinct patterns on the membrane of cultured neurons. We further identified an axonal targeting motif within the $\alpha 4$ loop and a dendritic targeting motif from the $\alpha 7$ loop. These findings may help to elucidate cellular mechanisms involved in the precise targeting of nicotinic receptors, a prerequisite for their proper physiological functions.

\section{Materials and Methods}

Molecular biology. Rat $\alpha 7, \alpha 4$, and $\beta 2 \mathrm{nAChR}$ subunits were each tagged by adding hemagglutinin (HA) or green fluorescent protein (GFP) at their $\mathrm{C}$ terminals. All new restriction sites were generated by PCR mutagenesis with the QuikChange protocol (Stratagene, La Jolla, CA). nAChR-HA and nAChR-GFP constructs were expressed in the mammalian expression vector pcDNA3 (Invitrogen, Carlsbad, CA) or pEGFP (Clontech, Mountain View, CA). The human interleukin 2 receptor $\alpha$ subunit (IL2RA) coding sequence was amplified by PCR from the pMLSV-N1/N4-s expression vector (American Type Culture Collection, Manassas, VA) and was further subcloned into pcDNA3. Dr. Gary Banker (Oregon Health \& Science University, Portland, OR) kindly provided transferrin receptor (TfR)-GFP. Postsynaptic density-95 (PSD-95)-GFP was provided by Dr. David Bret (University of California, San Francisco, CA). CD4 construct was provided by Dr. Lily Jan (University of California, San Francisco, CA). Tau-GFP was provided by Dr. John Thomas (The Salk Institute, La Jolla, CA), and GFP-NMDA receptor 1 (NR1) was provided by Dr. Stefano Vicini (Georgetown University, Washington, DC).

Cell culture preparation, DNA transfection, and protein staining. Hippocampal neurons from postnatal day 0 rats were cultured using standard techniques. After $\sim 1$ week in culture, cells were transfected using the calcium phosphate method. To detect proteins expressed on the cell surface, living cells were incubated with primary antibody diluted in culture medium for $10-15 \mathrm{~min}$ at room temperature, fixed (4\% paraformaldehyde and $4 \%$ sucrose for $20 \mathrm{~min}$ ), and processed for additional immunostaining. To detect total proteins, cells were fixed before permeabilization (1.5\% Triton X-100 in PBS buffer) and immunostaining. To detect internalized proteins, live neurons were incubated with primary antibody for $30 \mathrm{~min}$ at $37^{\circ} \mathrm{C}$, chilled in $4^{\circ} \mathrm{C}$ TBS to stop endocytosis, and then exposed to $0.5 \mathrm{M} \mathrm{NaCl} / 0.2 \mathrm{M}$ acetic acid, $\mathrm{pH} 3.5$, for $4 \mathrm{~min}$ on ice to remove surface-bound antibody. Cultures were subsequently rinsed, fixed, and permeabilized, followed by secondary antibody staining of internalized proteins. Antibodies/probes were used as follows: mice anti-HA (Covance, Princeton, NJ); rabbit anti-HA (Santa Cruz Biotechnology, Santa Cruz, CA); rabbit anti-GABA (Sigma-Aldrich, St. Louis, MO); chicken anti-GFP antibody (Clontech); rabbit anti-synapsin (Millipore, Billerica, MA); anti-PSD-95 monoclonal (Affinity BioReagents, Golden, CO); anti-CD4 monoclonal (Caltag Laboratories, South San Francisco, CA); anti IL2RA 
monoclonal (Covance); anti-microtubuleassociated protein 2 (MAP2) monoclonal (Sigma-Aldrich); rabbit anti-MAP2 (Millipore); rabbit anti-neurofilament (Millipore); Alexa $488 \alpha$-bungarotoxin (Invitrogen, Eugene, OR); Alexa dye-labeled secondary antibodies (Invitrogen); and cyanine 3 (Cy3)and Cy5-labeled secondary antibodies (Jackson ImmunoResearch, West Grove, PA).

Image analysis and processing. Neurons were imaged on an LSM 510 microscope (Zeiss, Thornwood, NY). Each cell was imaged as a stack of optical sections, $1 \mu \mathrm{m}$ in depth apart. The cell body was approximately in the center of each image. All calculations were performed on compressed images. All measurements were made with NIH ImageJ software. VolumeJ from the BIJ plugin packages was installed to ImageJ for three-dimensional (3D) reconstruction. The CorrelationJ 1e and JACoP plugins were used to calculate the overlap coefficient.

We used several methods to distinguish axons and dendrites. To facilitate morphological distinctions, GFP was coexpressed along with neuronal nAChRs to trace and visualize neurites. Previously defined morphological criteria were applied to distinguish neurites as axons or dendrites (Dotti et al., 1988). For example, dendrites have irregular contours, taper gradually, and branch at relatively acute angles. Axons, in contrast, display a smoother contour, have a relatively even diameter along their course, and extend much farther away from the cell body. Among these traits, particularly valuable in our study is the distinction that all of the long processes in the hippocampal culture represent axons (Dotti et al., 1988). This distinction was confirmed in our own experiments. We examined $>30$ GFP-transfected cells. In every case, neurites extending at least $250 \mu \mathrm{m}$ from the cell body corresponded to axons, based on their negative immunostaining of MAP2. In this study, we identified a neurite as an axon only when it extended at least $250 \mu \mathrm{m}$ from the cell body and also fitted other morphological distinctions described above (an example was provided in supplemental Fig. 5G-J, available at www.jneurosci.org as supplemental material). In addition to morphological criteria, axons and dendrites were further identified in some experiments based on a differential distribution of MAP2 (a dendritic marker) (supplemental Fig. 5A-F, available at www.jneurosci.org as supplemental material) and neurofilament (an axonal marker) (see Fig. 4). Dendritic protrusions were classified into two broad categories, spines and filopodia, based on criteria defined previously (Papa et al., 1995; Hering and Sheng, 2001). Briefly, a filopodia-like structure was identified if it was $>2 \mu \mathrm{m}$ in length with a base wider than the tip and did not terminate in enlarged heads, which is typical for spines.

Xenopus oocyte preparation, cDNA injection, and whole-cell current recording. Standard protocol was used for oocyte preparation. Subunit cRNAs were synthesized in vitro (Message Machine; Ambion, Austin, TX) from linearized plasmid templates. Whole-cell currents were measured at room temperature, 1-2 d after RNA injection, using a GeneClamp 500 amplifier (Molecular Devices, Union City, CA) in a standard two-microelectrode voltage-clamp configuration. Oocytes were clamped between -40 and $-65 \mathrm{mV}$ and superfused in ND96 containing $1.8 \mathrm{mM} \mathrm{CaCl}_{2}$ and $1 \mu \mathrm{M}$ atropine.
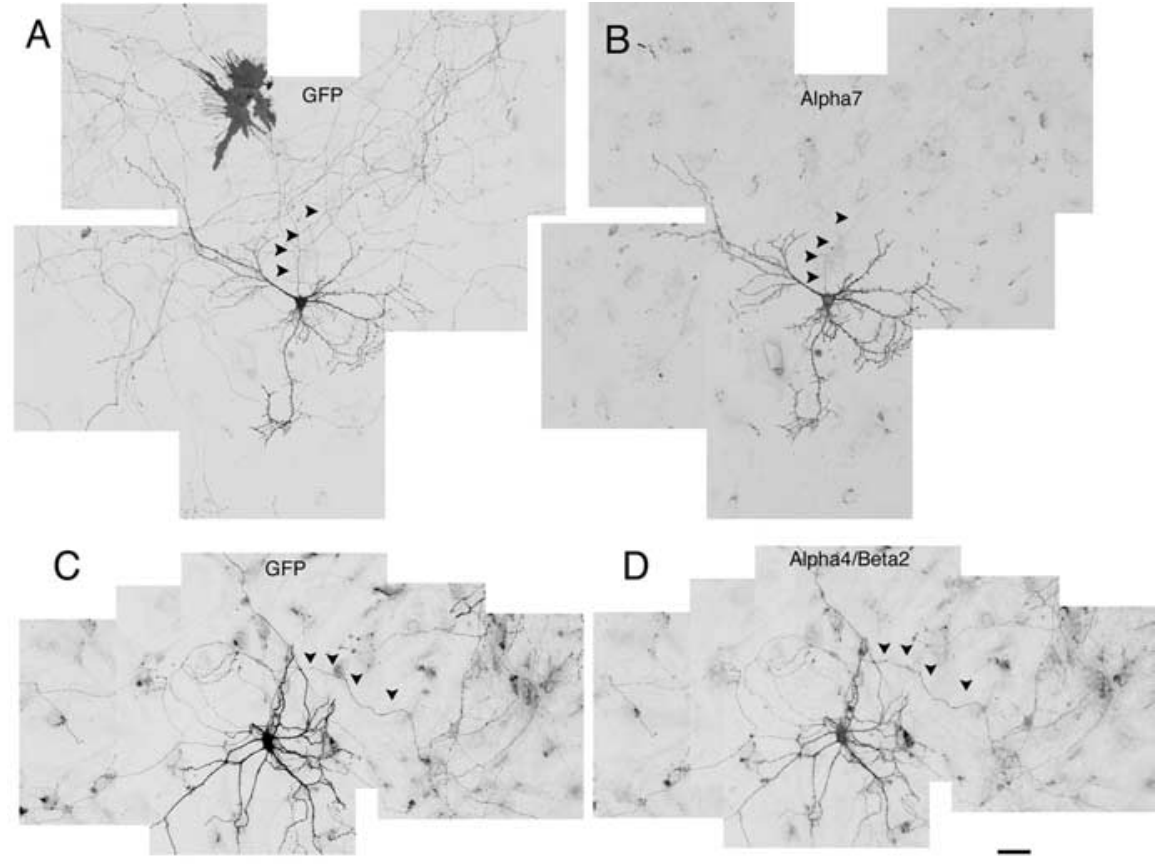

$\mathrm{E}$

Figure 2. Differential targeting of $\alpha 7$ and $\alpha 4 \beta 2$ expressed in cultured hippocampal neurons. $\boldsymbol{A}-\boldsymbol{D}$, Neurons were transfected at 8 DIV with $\alpha 7$-HA plus GFP. Surface receptor was labeled at 16 DIV with HA antibody. GFP fluorescence was used to outline neuronal morphology. Multiple images were taken from the LSM 510 confocal microscope and assembled to obtain a larger view. Unlike GFP $(\boldsymbol{A})$, surface $\alpha 7(\boldsymbol{B})$ was targeted to dendrites and excluded from axons (arrowheads). Low surface expression of $\alpha 7$ of $\alpha 7$ in transfected glia cells ( $\boldsymbol{A}$, top left) was below detection in $\boldsymbol{B}$. Surface expression of the $\alpha 4 \beta 2$ receptor $(\boldsymbol{D})$ was localized to (n) thansfected neuron also expressing GFP (C). Scale bar, $50 \mu \mathrm{m}$. Note that the surface $\alpha 4 \beta 2$ . $E-G$, Quantitative analysis of receptor polarization in neurons. $E$, Percentage of cells expressing recombinant proteins in s. Unike GFP and $\alpha 4 \beta 2$, surface expression of $\alpha 7$ at axons $\sim 200 \mu \mathrm{m}$ away from the cell body was detected in only $5 \%$ of ods in supplemental Fig. 1, available at www.jneurosci.org as supplemental material). G, Averaged intensity profiles of 列 supplemental material). The decay constant for $\alpha 7$ traveling along axons was estimated to be $45.6 \mu \mathrm{m}$. There is no reduction of $\alpha 4 \beta 2$ signal along axons. Error bars are SEM.

\section{Results}

C-terminally tagged receptors are expressed at the surface of transfected neurons and are capable of forming functional channels

To facilitate labeling, we first tagged the neuronal nAChRs by adding HA or GFP to their C terminals. Based on the topology of the receptor, tags at the $\mathrm{C}$ terminal are less likely to interfere with receptor trafficking than insertions at the $\mathrm{N}$-terminal or intracellular loop domains. We confirmed that tagged neuronal nAChRs were capable of forming functional channels with biophysical properties similar to those of wild-type receptors when expressed in Xenopus oocytes (Fig. $1 A-D$ ). Surface expression of tagged receptors could not be detected in human embryonic kidney (HEK) cells (data not shown), although internal expression was 


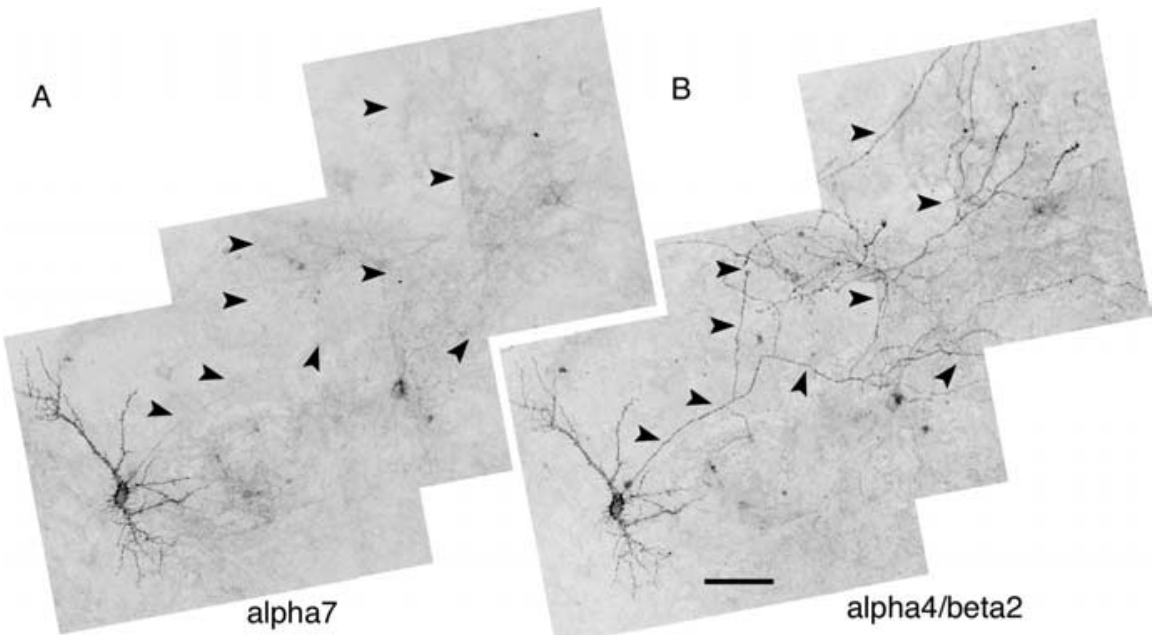

C

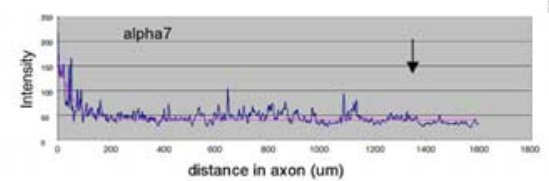

D
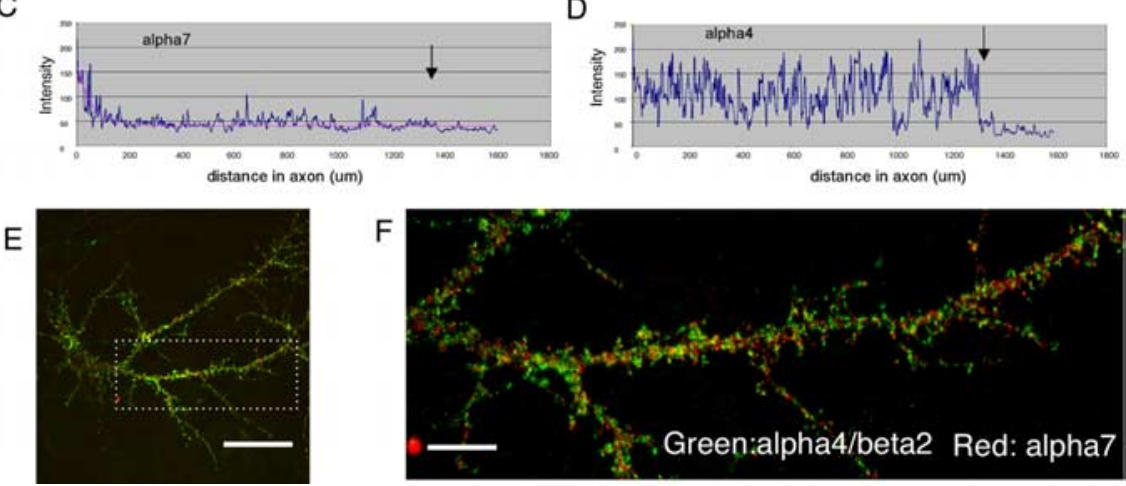

Figure 3. Direct comparisons of surface $\alpha 7$ and $\alpha 4 \beta 2$ in the same transfected neuron. $\boldsymbol{A}, \boldsymbol{B}$, Hippocampal neurons were cotransfected with $\alpha 7-$ GFP and HA-tagged $\alpha 4$ and $\beta 2(\alpha 4-\mathrm{HA} / \beta 2-\mathrm{HA})$ at 8 DIV. Surface $\alpha 7$ was stained by chicken anti-GFP antibodies, and surface $\alpha 4 \beta 2$ was stained by mouse anti-HA antibody at 16 DIV. Neurons were fixed and blocked before incubating with secondary antibody (Alexa 568-labeled goat anti-mouse and Alexa 647-labeled goat anti-chicken antibodies). Images were scanned from the LSM 510 confocal microscope. Pseudocolors were initially applied to represent surface signals of $\alpha 7$ (green) and $\alpha 4 \beta 2$ (red) before converting to gray channel. Multiple images were taken from the LSM 510 confocal microscope and were assembled to obtain a larger view. Surface $\alpha 7$ was mostly expressed in soma-dendrites; a faint signal can be detected at initial axonal regions, but it decreased below detection along the axons $(\boldsymbol{A})$. Surface $\alpha 4 \beta 2$ was expressed at both axons and soma-dendrites $(\boldsymbol{B})$. Arrowheads indicate axon regions. $\boldsymbol{C}, \boldsymbol{D}$, Intensity line profiles of $\alpha 7$ and $\alpha 4 \beta 2$ along axons from the transfected neuron shown in $\boldsymbol{A}$ and $\boldsymbol{B}$. Arrows mark the start of blank regions. $\boldsymbol{E}, \boldsymbol{F}$, Neurons were transfected and stained similarly to those in $\boldsymbol{A}$ and $\boldsymbol{B}$, except that staining was performed at 22 DIV. A neuron expressing both $\alpha 7-$ GFP and $\alpha 4-\mathrm{HA} / \beta 2-\mathrm{HA}$ is shown in $\boldsymbol{E}$. The boxed region from $\boldsymbol{E}$ is enlarged in $\boldsymbol{F}$. Although $\alpha 7$ and $\alpha 4 \beta 2$ were both expressed in somatodendritic compartments, a large fraction of surface clusters from different receptors did not overlap $(\boldsymbol{F})$. Scale bars: (in $\boldsymbol{B}) \boldsymbol{A}, \boldsymbol{B}, 100 \mu \mathrm{m} ; \boldsymbol{E}, 30 \mu \mathrm{m}$; $\boldsymbol{F}, 10 \mu \mathrm{m}$.

visualized by immunofluorescence and detected by Western blot analysis (data not shown).

We transfected cultured primary neurons with tagged $\alpha 7$ using the $\mathrm{CaPO}_{4}$ method. In marked contrast to HEK cells, neuronal surface expression of recombinant $\alpha 7$ was readily detectable by immunofluorescence (Fig. $1 E-J$ ). Furthermore, $\alpha 7$ surface expression detected by antibody staining resembled staining by $\alpha$-bungarotoxin (Fig. $1 E-J$ ), which binds with high affinity to assembled $\alpha 7$ receptors (Couturier et al., 1990; Kawai et al., 2002). Therefore, adding an epitope tag does not appear to interfere with receptor assembly. However, HA antibody staining yielded a higher signal/background ratio and better spatial resolution and was more suitable for examining the subcellular distribution in our experiments (Fig. $1 J$ ).

\section{Polarized expressions of $\alpha 7$ and $\alpha 4 \beta 2$ receptors in hippocampal neurons}

We first examined the axonal/somatodendritic distribution of neuronal nAChRs in cultured hippocampal neurons. GFP was coexpressed along with the tagged receptors to visualize cell morphology. To avoid labeling intracellular receptors that might confound our results, we initially stained surface receptors only by applying antibody to live neurons for a short period of time at room temperature (see Materials and Methods). The distributions of expressed receptors were examined in transfected neurons that had clearly identifiable axons and dendrites (see Materials and Methods). Surprisingly, surface $\alpha 7-\mathrm{HA}$ immunostaining was detected almost exclusively in dendrites (Fig. 2B). Much lower surface expression was detected at proximal axonal regions (within $\sim 100 \mu \mathrm{m}$ from the cell body), but the signal decreased sharply along the axonal process (Fig. $2 \mathrm{~B}$, arrows). Weak axonal immunoreactivity away from the cell body (beyond $\sim 200 \mu \mathrm{m}$ ) was detected in $5 \%$ of the transfected neurons (10 independent transfections) (Fig. 2E). In contrast, surface $\alpha 4 \beta 2$ was localized to both axons and dendrites (Fig. 2D) in all of the transfected neurons (Fig. 2E). As expected, surface expression was not detectable in cells transfected with $\alpha 4$ or $\beta 2$ alone (data not shown).

Quantitative examination of protein polarization is complicated by differences in the diameters of axons and dendrites, which result in a higher intensity in dendrites versus axons, even for proteins that are expressed ubiquitously, such as GFP. To more accurately assess receptor polarization, we used two methods for quantitative analysis (supplemental Fig. 1, available at www.jneurosci.org as supplemental material).

First, coexpressed GFP was used for normalization, as described previously (Rivera et al., 2003; Sampo et al., 2003). A value for normalized ratio of dendrite-toaxon expression (D/A) was derived by dividing the ratio of receptor density in dendrites versus axons by the corresponding ratio of GFP from the same cell (supplemental Fig. 1 $A-D$, available at www.jneurosci.org as supplemental material). This normalized D/A ratio should reflect the extent of polarization expression more precisely. In our study, D/A value was calculated for at least 20 different cells for each construct. The average D/A value for $\alpha 7$ was $12.94 \pm 0.68(n=20)$, indicating a preferential localization to the dendrite, significantly different from the D/A value for $\alpha 4 \beta 2(0.76 \pm 0.069 ; n=20 ; p<0.001)$ (Fig. $2 F$ ).

Second, we used GFP to visualize the axonal processes, and we analyzed the surface expression of recombinant proteins along the axons (supplemental Fig. $1 E-G$, available at www.jneurosci.org as supplemental material). As seen in Figure $2 B$ and supplemental Figure $1 E$ (available at www.jneurosci.org as supplemental material), the intensity of surface $\alpha 7$ decreased drastically down the axons. In fact, such a decline fits well with single-exponential decay with a distance constant of $45.6 \mu \mathrm{m}(n=14)$ (Fig. $2 G)$. Unlike $\alpha 7, \alpha 4 \beta 2$ surface expression level did not vary along axons (Fig. $2 D, G$ ). 
It has been established that distinct mechanisms underlie specific targeting of neuronal membrane proteins (Silverman et al., 2001; Sampo et al., 2003). In the case of $\alpha 7$, the absence of axonal surface expression may arise from either the absence of axonal transport or the absence of subsequent membrane insertion and stabilization. To distinguish between these two possibilities, we used permeabilized cells to stain intracellular as well as surface proteins. If $\alpha 7$ was transported but not inserted into the membrane, then axonal staining would be expected in permeabilized cells. Instead, we observed a predominant dendritic localization of total $\alpha 7$ (supplemental Fig. 2D-F, available at www.jneurosci.org as supplemental material) $(\mathrm{D} / \mathrm{A}, 12.4 \pm 0.55 ; n=20)$, similar to surface $\alpha 7$ (D/A, $12.94 \pm 0.68 ; n=20)$. Thus, selective transport is likely to account for polarized expression of $\alpha 7$, resembling the mechanism of dendritic targeting observed for Kv4.2 potassium channels (Rivera et al., 2003) and TfRGFP (Silverman et al., 2001).

To more directly compare the expressions of $\alpha 7$ and $\alpha 4 \beta 2$ within one cell, we cotransfected GFP-tagged $\alpha 7$ ( $\alpha 7-\mathrm{GFP})$ and HA-tagged $\alpha 4$ and $\beta 2$ into primary neurons. We used double labeling with antibodies to GFP and HA to visualize surface $\alpha 7$ and $\alpha 4 \beta 2$ simultaneously. Consistent with previous results, subcellular expression profiles of $\alpha 7$ and $\alpha 4 \beta 2$ in the same neurons were quite distinctive, with surface $\alpha 7$ localized preferentially to somatodendritic compartments, in contrast to surface $\alpha 4 \beta 2$, which was detected at both axons and dendrites (Fig. $3 A-D$ ). Even in dendrites in which both $\alpha 7$ and $\alpha 4 \beta 2$ were expressed, a fraction of $\alpha 7$ clusters did not colocalize with those of $\alpha 4 \beta 2$ (Fig. 3E-F) (Pearson's coefficient, $r=$ $0.56 \pm 0.04 ; n=6)$. This result once again indicates that distinct targeting mechanisms are used for different $\mathrm{nAChR}$ subunits.

\section{Comparisons of surface nAChRs to neuronal subcellular markers}

In addition to morphological criteria, we also used MAP2 staining and neurofilament staining to discriminate between somadendrites and axons. Consistent with previous conclusions, $\alpha 7$ was present within dendrites marked by MAP2 antibody (Fig. $4 A, B$, supplemental Fig. 5A-C, available at www.jneurosci.org as supplemental material) but was absent from axons labeled with neurofilament antibody (Fig. 4E-G). When coexpressed with other markers, $\alpha 7$ expression overlapped with TfR-GFP (supplemental Fig. 3A-C, available at www.jneurosci.org as supplemental material), a dendritic marker (Silverman et al., 2001), but not with Tau-GFP (Fig. $4 A, C$ ), a protein marker highly expressed in axons (Callahan et al.,
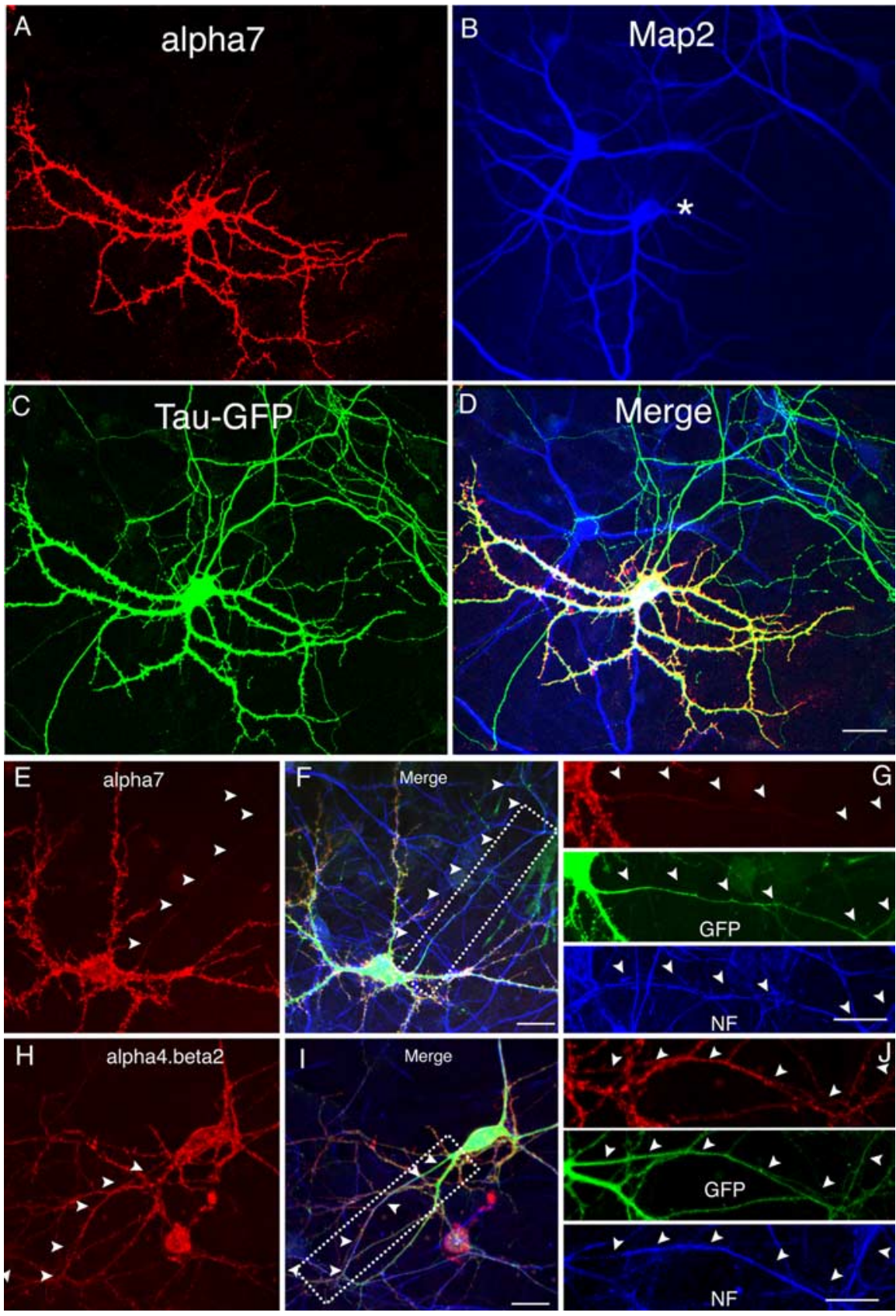

Figure 4. Comparison of $\alpha 7$ and $\alpha 4 \beta 2$ with dendritic and axonal markers. A-D, $\alpha 7-\mathrm{HA}$ was cotransfected with Tau-GFP into cultured neurons at 8 DIV and stained at 12 DIV. Surface $\alpha 7(\boldsymbol{A})$ was MAP2 positive $(\boldsymbol{B})$ but did not overlap with Tau-GFP in axons (C). $\boldsymbol{D}$, Merged images of $\boldsymbol{A}-\boldsymbol{C}$. The asterisk in $\boldsymbol{B}$ indicates the transfected neuron. $\boldsymbol{E}-\boldsymbol{G}, \mathrm{HA}$-tagged receptor subunits were cotransfected with GFP into cultured neurons at 8 DIV. Neurons were triple labeled with surface $\alpha 7$ or $\alpha 4 \beta 2$ (red), GFP (green), and neurofilament (blue) at 12 DIV $(\boldsymbol{F}, I)$. Surface $\alpha 7(\boldsymbol{E})$ was mostly excluded from axons labeled by neurofilament antibody $(\boldsymbol{F}$, $\boldsymbol{G}$ ). In contrast, surface $\alpha 4 \beta 2(\boldsymbol{H})$ was found in neurofilament-positive axonal fibers $(\boldsymbol{I}, \boldsymbol{J})$. Boxed regions in $\boldsymbol{F}$ and $\boldsymbol{I}$ are shown with separated channels at higher magnification in $\boldsymbol{G}$ and $\boldsymbol{J}$, respectively. Arrowheads mark axons. NF, Neurofilament. Scale bars: (in $\boldsymbol{D}$ ) $\boldsymbol{A}-\boldsymbol{D}, 50 \mu \mathrm{m} ;$ (in $F, G, I, J) E-J, 25 \mu \mathrm{m}$.

1998). Altogether, these results confirmed that surface-expressed $\alpha 7$ was highly restricted to somatodendritic compartments. In contrast, $\alpha 4 \beta 2$ staining was found in axons labeled with neurofilament antibody (Fig. $4 H-J$ ) as well as dendrites labeled by MAP2 antibody (supplemental Fig. 5D-F, available at www.jneurosci.org as supplemental material). Using a different set of markers, $\alpha 4 \beta 2$ staining was found in both dendrites and axons, labeled by TfR-GFP (supplemental Fig. 3D-F, available at www.jneurosci.org as supplemental material) and Tau-GFP (supplemental Fig. $4 D-F$, available at www. jneurosci.org as supplemental material), respectively. 

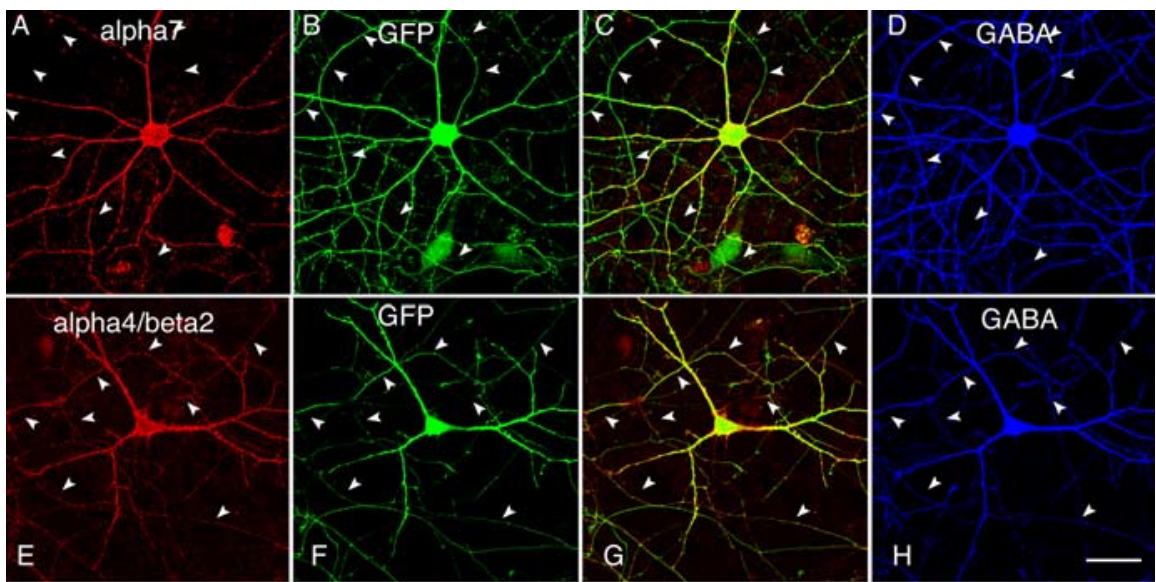

Figure 5. Differential targeting of $\alpha 7$ and $\alpha 4 \beta 2$ in GABAergic neurons. $\boldsymbol{A}-\boldsymbol{D}$, Transfected GABAergic neuron triple labeled with surface $\alpha 7(\boldsymbol{A}), \mathrm{GFP}(\boldsymbol{B})$, and GABA $(\boldsymbol{D})$. C, Merged $\boldsymbol{A}$ and $\boldsymbol{B}$. Surface $\alpha 7$ was not detected in axons (arrowheads). $\boldsymbol{E}-\boldsymbol{H}$, Transfected GABAergic neuron triple labeled with surface $\alpha 4 \beta 2(\boldsymbol{E})$, GFP $(\boldsymbol{F})$, and GABA $(\boldsymbol{H})$. $\boldsymbol{H}$, Merged $\boldsymbol{E}$ and $\boldsymbol{F}$. Surface $\alpha 4 \beta 2$ resided in axons and dendrites of GABAergic neurons. Scale bar, $50 \mu \mathrm{m}$.
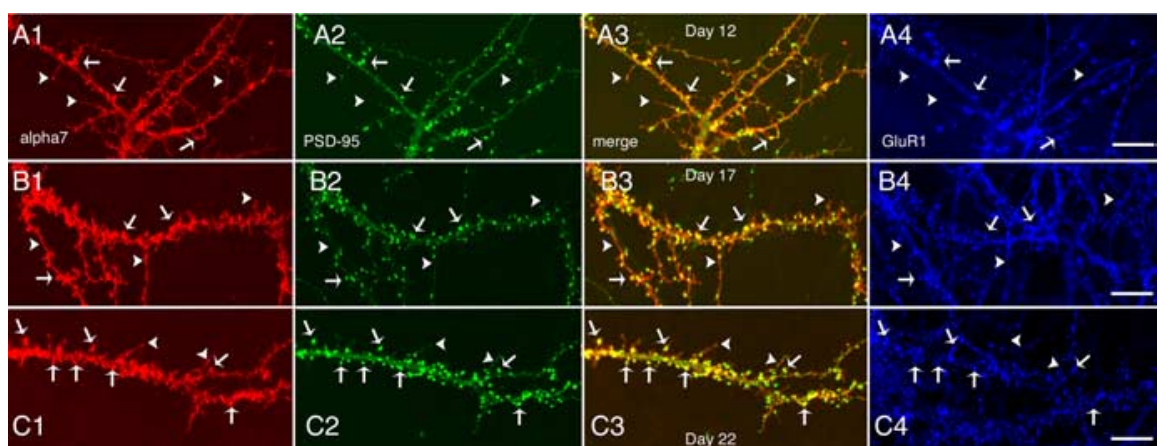

Figure 6. The locations of $\alpha 7$ at spines and filopodia-like structures. Shown are dendritic regions from hippocampal neurons cotransfected with $\alpha 7-H A$ and PSD-95-GFP at 8 DIV. Cultures at 12 (A1-A4), 17 (B1-B4), and 22 (C1-C4) DIV were triple labeled with surface $\alpha 7$, PSD-95-GFP, and endogenous GluR1. Arrowheads label colocalized puncta of $\alpha 7$, PSD-95, and GluR1. Arrows point to locations at the tip or neck of filopodia-like structures at which $\alpha 7$ was present, but PSD-95 and GluR1 were not. Spine synapses were more evident in older neurons. The fraction of filopodia-like structures decreases progressively as the neurons mature. Consistent with this time course, $\alpha 7$ distribution was shifted to punctate clustering similar to that of PSD-95 and GluR1. The overall Pearson's coefficient of $\alpha 7$ to PSD-95 increased from $0.71 \pm 0.024$ ( $n=10 ; 12$ DIV) to $0.78 \pm 0.022$ ( $n=10$; 17 DIV; $p=0.037, t$ test $)$ and farther to $0.82 \pm 0.025$ ( $n=10 ; 22$ DIV; $p=0.26, t$ test, 17 vs 22 DIV). Scale bars, $15 \mu \mathrm{m}$.

\section{Surface expression of nAChRs in hippocampal GABAergic neurons}

In the hippocampus, neuronal nAChRs are distributed on both the excitatory pyramidal neurons (McGehee et al., 1995; Gray et al., 1996) and the inhibitory GABAergic interneurons (Jones and Yakel, 1997; Frazier et al., 1998a; Alkondon et al., 2000; Khiroug et al., 2003). A large body of evidence indicates that neuronal nAChRs in the GABAergic neurons can modulate synaptic transmission and influence inhibitory activity in the brain (Alkondon et al., 1997; Frazier et al., 1998b; Ji et al., 2001). We next examined the distribution of receptors in GABAergic neurons $(\sim 4-8 \%$ of the neurons in our preparation). Hippocampal cultures were stained with anti-GABA antibody for the identification of GABAergic neurons (Fig. 5D,H). Analysis of transfected GABAergic cells ( $>20$ cells from multiple transfections) demonstrated the predominant surface expression of $\alpha 7$ in the somatodendritic compartment (Fig. 5A-D), compared with ubiquitous expression of $\alpha 4 \beta 2$ in both axons and dendrites (Fig. $5 E-H$ ). Thus, we found that the distribution of neuronal nAChRs was similar in both inhibitory and excitatory neurons.

\section{Synaptic locations of $\mathbf{n A C h R s}$ in} hippocampal neurons

Because neuronal nAChRs play important roles in synaptic transmission (McGehee et al., 1995; Gray et al., 1996; Mansvelder and McGehee, 2000; Ji et al., 2001), we next inspected the synaptic locations of $\alpha 7$ and $\alpha 4 \beta 2$ in cultured hippocampal neurons. We cotransfected HA-tagged $\alpha 7$ with postsynaptic marker PSD-95-GFP (Fig. 6). On neurons $12 \mathrm{~d}$ in vitro (DIV) in culture, the patches of $\alpha 7$ subunits on dendrites often colocalized with the postsynaptic marker PSD-95-GFP (Fig. 6A1-A3, arrows), in agreement with previous findings of the postsynaptic location of $\alpha 7$ (Liu et al., 2001; Kawai et al., 2002). Interestingly, $\alpha 7$ was also frequently observed at long necks and tips of the filopodia-like structures (Fig. 6A1, arrowheads), a phenomenon described previously from GABAergic neurons (Kawai et al., 2002). Because it is not always easy to distinguish filopodia from spines based on morphology standards, we also used glutamate receptor 1 (GluR1) staining, which was shown previously to form clusters almost exclusively at dendritic spines (Rao et al., 1998), as a marker. We found that the majority of PSD-95-GFP puncta were positive in $\alpha 7$ and GluR1 staining (arrows). However, at the tip or neck of thin structures that look like filopodia (arrowheads), only $\alpha 7$ staining was found, whereas both PSD-95 and GluR1 were absent or did not appear as punctate clusters (Fig. 6A1-A4). To determine whether the location of $\alpha 7$ in dendrites follows a developmental pattern, we examined its distribution from neurons with different days in culture. In confirmation of previous studies (Papa et al., 1995; Boyer et al., 1998), the fraction of filopodia-like structures decreased and the density of spine synapses increased as cultures matured (Fig. 6A2,B2,C2). Consistent with this time course, the distribution of $\alpha 7$ was also shifted to structures that showed concentrated clustering of PSD-95 and GluR1. The overall Pearson's coefficient of $\alpha 7$ to PSD-95-GFP increased from $0.71 \pm 0.024$ $(n=10 ; 12 \mathrm{DIV})$ to $0.78 \pm 0.022(n=10 ; 17 \mathrm{DIV} ; p=0.037 ; t$ test $)$ and up to $0.82 \pm 0.025(n=10 ; 22 \mathrm{DIV} ; p=0.26 ; t$ test, 17 vs $22 \mathrm{DIV})$. Even at $22 \mathrm{DIV}$, when dendritic spines with distinct spiny heads were more evident (Fig. 6C2), $\alpha 7$ can still be seen in the few visible long filopodia. Together, these results confirm that $\alpha 7$ may be expressed at both mature synapses and filopodia-like structures in hippocampal neurons.

To further analyze the synaptic locations of $\alpha 7,3 \mathrm{D}$ reconstructions were performed from confocal image stacks. Surfaceexpressed $\alpha 7$ was often concentrated in discrete clusters within dendritic spines of mature neurons (Fig. 7C). Furthermore, $\alpha 7$ clusters usually were in close contact but not overlapped with presynaptic clusters labeled with anti-synapsin antibody (Fig. $7 B, D$ ) (Pearson's coefficient, $r=0.369$; Manders' coefficients, $\mathrm{M} 1=0.141$, which represents the fraction of synapsin overlap- 
ping $\alpha 7$ ). (Note that calculation based on compressed images tends to overestimate the degree of overlapping. The actual overlapping coefficient is likely to be even smaller.) Finally, double labeling of tagged $\alpha 7$ (Fig. 7E, F, green) and endogenous PSD-95 (Fig. $7 E, F$, red) revealed a high degree of colocalization in mature neurons (22 DIV; note that PSD-95 puncta outside of $\alpha 7$ were from nontransfected cells). All of these results are consistent with the location of $\alpha 7$ at or close to postsynaptic sites.

We also examined possible synaptic locations of $\alpha 4 \beta 2$, in addition to $\alpha 7$ (Fig. 8). In the somatodendritic compartments, a number of $\alpha 4 \beta 2$-positive clusters were also apposed to endogenous presynaptic clusters labeled by anti-synapsin antibody (Fig. $8 B, D$ ), similarly to $\alpha 7$ (Fig. $8 A, C$ ). However, $\alpha 4 \beta 2$ clusters were also distributed with presynaptic clusters in axons (Fig. $8 F$ ), in contrast to the absence of $\alpha 7$ in these regions (Fig. $8 E$ ). Like $\alpha 7$ in dendrites (Fig. $8 G$ ), fractions of $\alpha 4 \beta 2$ clusters were also found to overlap with PSD-95GFP clusters (Fig. $8 \mathrm{H}$ ), with a degree of correlation not significantly different from that of $\alpha 7$ (Pearson's $r=0.67 \pm 0.04$ for $\alpha 4 \beta 2, n=8,12-14 \mathrm{DIV} ; r=0.71 \pm 0.02$ for $\alpha 7, n=10,12-13$ DIV; $p>0.05$, $t$ test; Pearson's coefficients were calculated by ImageJ with soma regions excluded for analysis).

Finally, we cotransfected tagged $\alpha 7$ or $\alpha 4 \beta 2$ with presynaptic marker synaptophysin-GFP (Fig. 9). There is very little overlap between $\alpha 7$ and synaptophysin (Fig. $9 A, B$ ), other than in the cell bodies (Fig. 9A,B, inset), consistent with the absence of $\alpha 7$ in axons (Fig. 2). Both $\alpha 4 \beta 2$ and synaptophysin-GFP were expressed along axon fibers, although $\alpha 4 \beta 2$ was distributed more uniformly compared with synaptophysin-GFP (Fig. 9C,D). More than $60 \%$ of the synaptophysin-GFP clusters, the expression of which often associates with functional presynaptic compartments (Y. Zhu and C. F. Stevens, unpublished data), were colocalized with $\alpha 4 \beta 2$-positive clusters (Fig. 9E). Colocalization analysis also revealed a high degree of correlation between synaptophysin-GFP and $\alpha 4 \beta 2$ (Pearson's coefficient, $r=0.65 \pm$ 0.06; $n=6$ cells, $>2000$ clusters) (Fig. $9 F$ ).

\section{M3-M4 loops contain subcellular targeting sequences}

Sequences from several groups of membrane proteins have been identified to mediate dendritic or axonal targeting (Stowell and Craig, 1999; Ruberti and Dotti, 2000; Garrido et al., 2001; Gu et al., 2003; Rivera et al., 2003). It is thus natural to speculate that specific sequences act as signals within neuronal nAChRs to mediate subcellular targeting. We examined the M3-M4 intracellular loop for several reasons. First, primary sequences in the M3-M4 loop are the most diverse among different receptors (Le Novere et al., 1999; Corringer et al., 2000) (see Fig. 11C for sequence alignment). This may be consistent with the diversity of polarized expression observed for different receptors. Second, M3-M4 loops compose the largest cytoplasmic domain within neuronal nAChRs that is likely to interact with the machinery involved in the protein sorting, trafficking, and membrane inser- tion. Indeed, it has been demonstrated that the M3-M4 loop from chick $\alpha 3$ subunit targets this receptor to subdomains within individual synapses on developing chick ciliary ganglion (CG) neurons in vivo (Williams et al., 1998; Temburni et al., 2000).

We constructed a series of chimeras by swapping M3-M4 loops among the $\alpha 4, \alpha 7$, and $\beta 2$ subunits. However, surface expression was not observed from cells expressing chimeras alone or in various combinations (data not shown). To determine whether M3-M4 loops contain subcellular localization motifs, we attached loop sequences to the $\mathrm{C}$ terminal of the $\mathrm{CD} 4$ protein, a transmembrane protein that localizes nonspecifically in neurons (see Fig. 10J) (Gu et al., 2003). Consistent with previous reports, surface expression of CD4 was not polarized in our study $(\mathrm{D} / \mathrm{A}, 0.78 \pm 0.10 ; n=20)$ (Fig. $10 A-C$ ). The addition of the M3-M4 loop from $\alpha 7$ caused the resulting fusion protein, CD4$\alpha 7$, to localize to the soma-dendrites (D/A, $6.52 \pm 0.46 ; n=20$ ) (Fig. 10G-I). This was in marked contrast to the localization of CD $4-\alpha 4(\mathrm{D} / \mathrm{A}, 0.09 \pm 0.015 ; n=20)($ Fig. $10 D-F)$. The difference in the pattern of expression was significant $(p<0.001)$. The CD4- $\beta 2$ was not expressed to the surface of transfected neurons (data not shown). In summary, these results demonstrate that the M3-M4 loop can function out of the context of neuronal nAChRs to mediate axonal/dendritic targeting and strongly suggest that M3-M4 loops are involved in the targeting of neuronal nAChRs.

Identifying sequence motifs that target neuronal nAChRs to dendrites and axons

To further identify the critical determinants in the $\alpha 4$ and $\alpha 7$ loops, a series of C-terminal or N-terminal truncations or inter- 

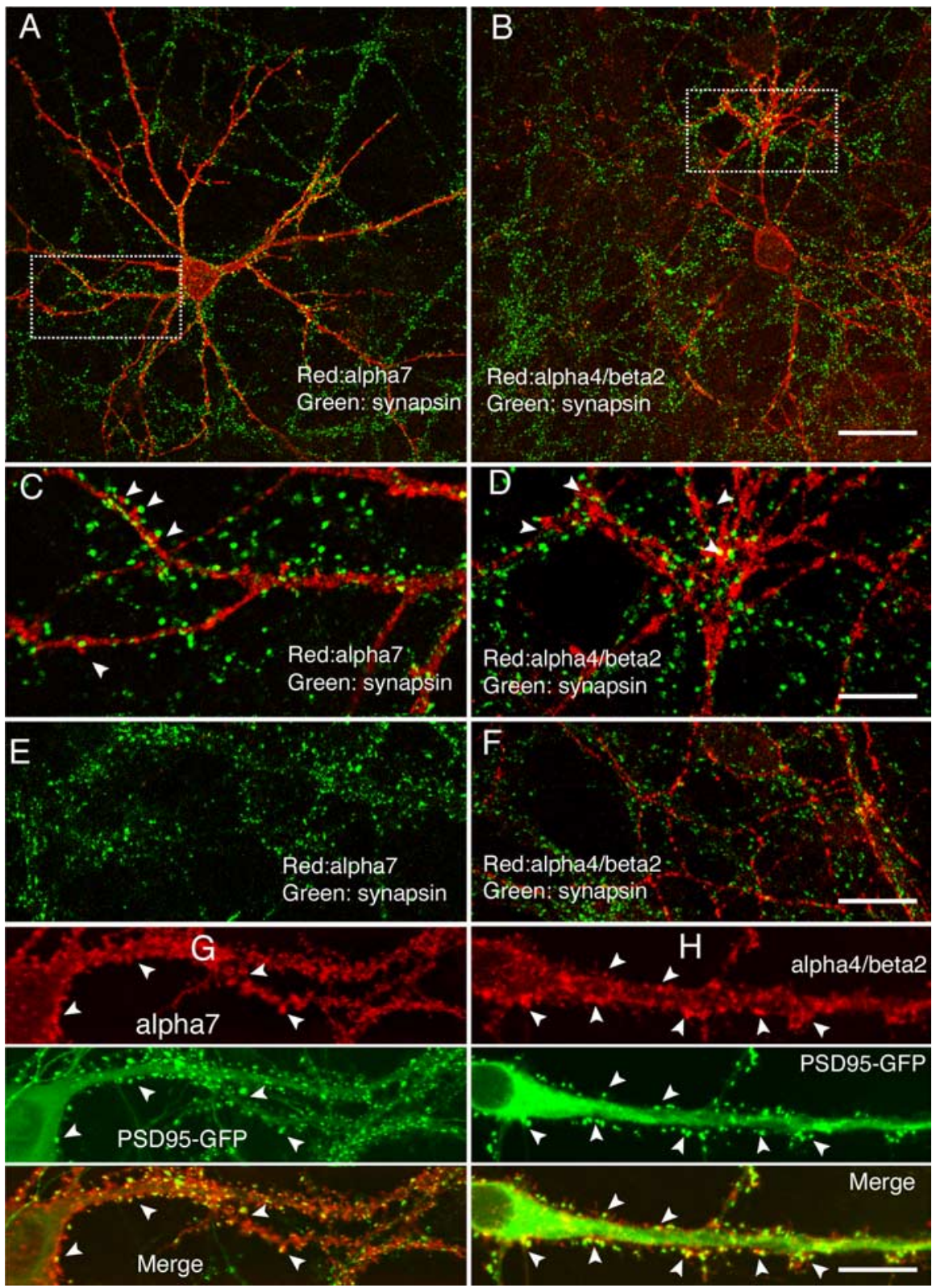

Figure 8. Synaptic locations of recombinant $\alpha 4 \beta 2$. $\boldsymbol{A}-\boldsymbol{F}$, Neurons transfected with tagged $\alpha 7(\boldsymbol{A})$ or $\alpha 4 \beta 2(\boldsymbol{B})$ were surface labeled with mouse anti-HA antibodies (red), followed by labeling with rabbit anti-synapsin antibodies at 16 DIV (green). C, D, Enlarged images from the boxed regions in $\boldsymbol{A}$ and $\boldsymbol{B}$, respectively. Note that the clusters of $\alpha 7$ from the dendritic region were often in close contact with presynaptic clusters ( $\boldsymbol{C}$, arrowheads). Fractions of $\alpha 4 \beta 2$ clusters were also in close contact with presynaptic marker ( $\boldsymbol{D}$, arrowheads). Small regions $\sim 300 \mu \mathrm{m}$ from the cell body in which axons were located were shown from $\alpha 7$ transfected cells $(\boldsymbol{E})$ or $\alpha 4 \beta 2$-transfected cells $(\boldsymbol{F}) . \mathbf{G}, \boldsymbol{H}$, Neurons transfected at 8 DIV with tagged $\alpha 7(\boldsymbol{G})$ or $\alpha 4 \beta 2(\boldsymbol{H})$ plus PSD-95-GFP (middle) were surface labeled with anti-HA antibodies (top) at 14 DIV. A number of overlapped clusters were indicated by arrowheads (bottom). Within the somal area, PSD-95-GFP was observed in a perinuclear distribution, typical for intracellular proteins. Scale bars: (in $\boldsymbol{B}) \boldsymbol{A}, \boldsymbol{B}, 50 \mu \mathrm{m}$; (in $\boldsymbol{D}) \boldsymbol{C}, \boldsymbol{D}, 20 \mu \mathrm{m}$; (in $\boldsymbol{F}) \boldsymbol{E}, \boldsymbol{F}, 20 \mu \mathrm{m}$; (in $\boldsymbol{H}) \boldsymbol{G}, \boldsymbol{H}, 20 \mu \mathrm{m}$.

ing sequence within the $\alpha 4$ loop (residues 30-54) (Fig. 11A) and a dendritic targeting sequence from the $\alpha 7$ loop (residues 33-80) (Fig. 11B). The amino acid sequences for both motifs are illustrated in Figure $11 D$.

Multiple signals that consist of short sequences of amino acid residues have been identified previously to mediate membrane sorting and endocytosis (Bonifacino and Traub, 2003). Interestingly, some of these signals have also been implicated in basolateral targeting in polarized epithelial cell and axon/dendrite targeting in neurons (Rivera et al., 2003). Close examination of targeting sequences revealed several potential motifs, such as a leucine-based signal and tyrosine-based signal (Fig. 11D). To test the hypothesis that these short motifs might be involved in the targeted expression of the receptor, mutations were introduced to either $\alpha 7-\mathrm{HA}$ or CD $4-\alpha 4$, which we found to be the most polarized to either dendrites or axons, respectively (Figs. $2 F, 10 \mathrm{~K}$ ). Three amino acid changes (LIE/AAA) in the leucine-based motif ([DE]XXXL[LI]) from the $\alpha 4$ axonal targeting sequence (Fig. $11 D$, top) almost abolished axonal targeting of CD $4-\alpha 4$ (Fig. 12A,C). In contrast, mutation of the FW sequence (FWP/AAA) had little effect (Fig. 12C). The $\alpha 7$ dendritic targeting sequence (Fig. $11 D$, bottom) comprises a stretch of 6 aa (LLYIGF) that may include both dileucine and YXX $\phi$ motifs. Mutating three critical residues in these motifs (LLY to AAA) led to a fivefold decrease in D/A ratio (Fig. 12B,D), whereas mutations in the diarginine sequence (PRR/ AAA) had little influence on D/A ratio (Fig. 12D). Furthermore, mutations within either the YXX $\phi$ motif (YIG/AAA and IGF/AAA) or the dileucine motif (LL/AA mutant) all resulted in reductions of D/A ratios (Fig. 12D), suggesting that both motifs participated in dendritic targeting of $\alpha 7$, although the $\mathrm{YXX} \phi$ motif might play more important roles, because larger decreases in D/A ratios were observed from the YIG/AAA and IGF/AAA mutations than from the LL/AA mutation (Fig. 12D).

Axonal targeting signal in the $\alpha 4$ loop is

nal fragments of M3-M4 loops from the $\alpha 4$ (Fig. 11A) and $\alpha 7$ (Fig. $11 B$ ) subunits were fused to another nontargeted protein, IL2RA (IL2RA was chosen instead of CD4 to facilitate screening because of its higher surface expression in our system). Positions of amino acids are based on the sequence alignment of the loop sequences shown in Figure 11C. All IL2RA fusion proteins were transfected into cultured hippocampal neurons. Ratios of polarized expression were determined by comparing with coexpressed GFP (Fig. 11A, $B$, right columns). Analysis of surface distributions from these constructs identified a 25 -residue axonal target-

\section{inactive in the assembled $\alpha \mathbf{4} \beta 2$ complex}

Although the M3-M4 loop from $\alpha 4$ was able to confine nonpolarized proteins (CD4 and IL2RA in our experiments) exclusively to the axonal surface (Figs. $10 D, E, 11 A, 12 A$ ), assembled $\alpha 4 \beta 2$ was expressed more uniformly in axons and dendrites. There are two possibilities: either the axonal targeting signal in $\alpha 4$ was not active (for instance, it might be "masked" in the assembled $\alpha 4 \beta 2$ complex) or there might be competing signals in the $\beta 2$ sequence or other regions in the $\alpha 4$ sequence that promote dendritic expression. 
If $\alpha 4$-targeting signal is actively involved in targeting of $\alpha 4 \beta 2$, then mutations within this signal are predicted to affect $\alpha 4 \beta 2$ subcellular distribution. However, unlike the (LIE/AAA) mutations in CD4- $\alpha 4$, which almost abolished axonal targeting (Fig. 12A), the same mutations introduced in the $\alpha 4$ subunit only resulted in a modest change in D/A ratio when coexpressed with the $\beta 2$ subunit $(0.83 \pm 0.073, n=20$, compared with $0.76 \pm 0.069$ from wild-type $\alpha 4 \beta 2, n=$ 20). This difference was not statistically significant ( $p=0.49 ; t$ test), suggesting that axonal signal from $\alpha 4$ does not play active roles in the $\alpha 4 \beta 2$ complex.

Next, we sought to determine whether there might be targeting signals in the M3-M4 loop of $\beta 2$ subunits. Because attaching a full $\beta 2$ loop to CD4 and IL2RA precluded surface expression, we adhered IL2RA to different regions from the $\beta 2$ loop. Fusion of IL2RA to the first 30 aa from the $\beta 2$ loop abolished surface expression (data not shown). In contrast, the chimeric protein with a truncated $\beta 2$ loop that lacks the first 30 aa (IL2RA- $\beta 2$ 31126) was expressed on neuronal surface in a nonpolarized pattern (D/A, $0.89 \pm 0.13$; $n=10$ ) (supplemental Fig. 5G-J, available at www.jneurosci.org as supplemental material), suggesting that the $\beta 2$ loop region (31-126) does not contain a subcellular targeting signal. Although we cannot positively exclude the possibility of the existence of a subcellular targeting signal in the first 30 aa of the $\beta 2$ loop, sequence examination suggests that it is less likely, because this region is rather hydrophobic (Ren et al., 2005) and thus unlikely to be exposed in folded protein. In fact, residues in this region were implicated in early stages of receptor biogenesis, such as subunit assembly (Yu and Hall, 1994) and endoplasmic reticulum (ER) export (Ren et al., 2005), that take place before vesicle sorting, transporting, and endocytosis events, which regulate polarized expression (Horton and Ehlers, 2003).

With very few exceptions (Sampo et al., 2003), almost all known neuronal targeting signals were found in cytoplasmic regions of membrane proteins. Another cytoplasmic domain in neuronal nAChRs, the M1-M2 loop, might be too short (only 6 aa, with an almost identical sequence among all neuronal nAChRs) to hold functional targeting signals, as was confirmed by nonpolarized expression pattern when these short loops were attached to CD4 (data not shown). Whether or not targeting signals may exist in other regions in the $\beta 2$ and $\alpha 4$ sequences remains to be determined experimentally. In summary, we found that mutation of key residues in the axonal targeting motif of $\alpha 4$ did not affect surface distribution of the $\alpha 4 \beta 2$ receptor. We did not find other targeting signals in $\beta 2$ and $\alpha 4$ sequences from the regions we examined. Alto-
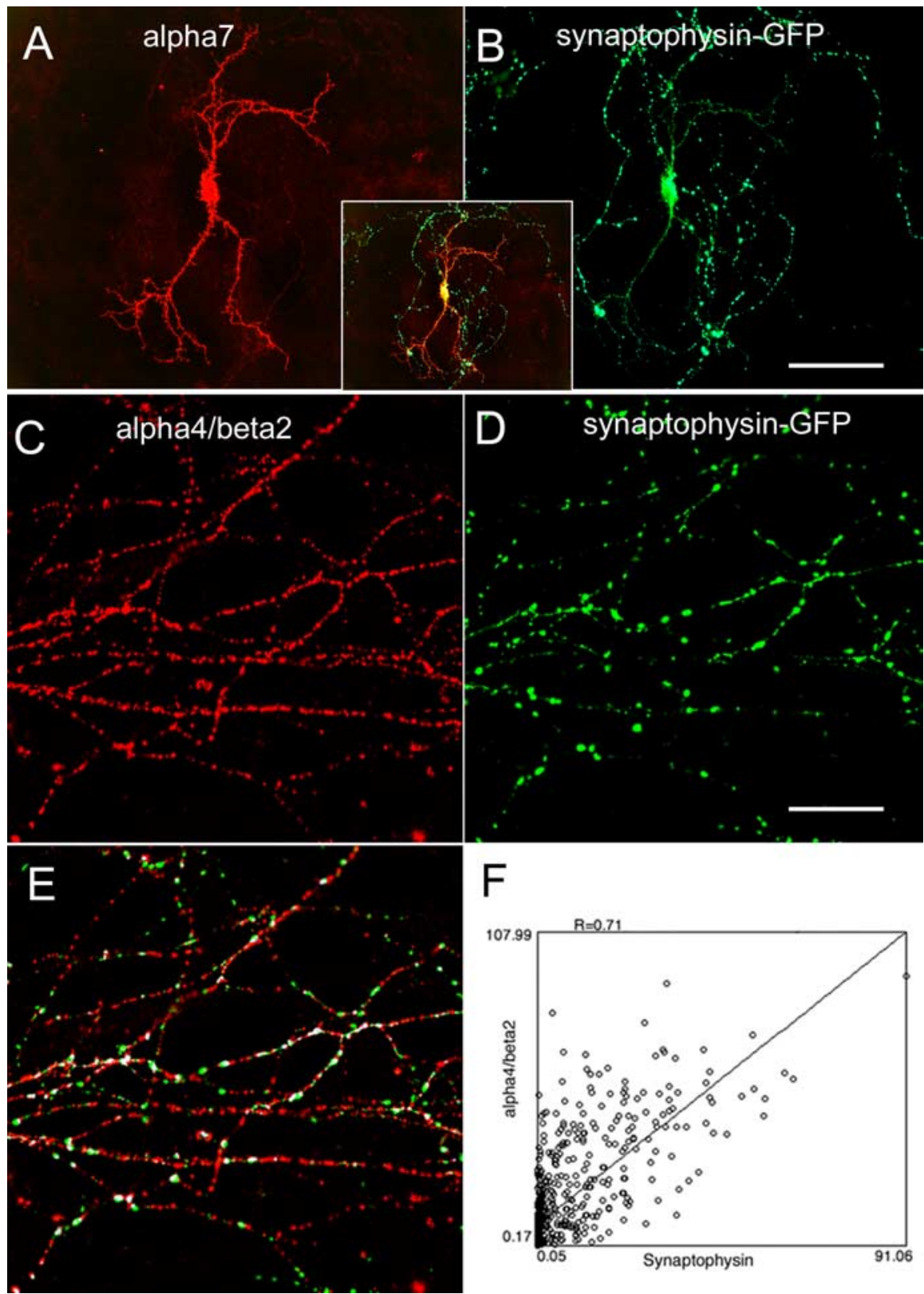

Figure 9. Comparisons of $\alpha 7$ and $\alpha 4 \beta 2$ with synaptophysin-EGFP (enhanced GFP). Neurons were transfected with recombinant neuronal nAChRs plus synaptophysin-GFP at 8 DIV. Surface receptors were labeled with mouse anti-HA antibodies at 16 DIV. $\alpha 7(\boldsymbol{A})$ did not overlap with synaptophysin-GFP $(\boldsymbol{B})$, except for cell bodies (inset). Both $\alpha 4 \beta 2$ and synaptophysin-GFP were expressed along axons, although $\alpha 4 \beta 2$ was distributed more uniformly $(\boldsymbol{C})$ than synaptophysin-GFP $(\boldsymbol{D})$. More than $60 \%$ of the synaptophysin-GFP clusters were colocalized with $\alpha 4 \beta 2$ (E; colocalized clusters were labeled in white). The correlation coefficient was further calculated using ImageJ (CorrelationJ 1e plugin; $\boldsymbol{F}$ ).

gether, it is possible that the difference of axonal expression of fusion proteins containing the $\alpha 4$ loop (CD $4-\alpha 4$ and IL2RA$\alpha 4)$ versus nonpolarized expression of the $\alpha 4 \beta 2$ receptor may be caused by "inactivation" or masking of axonal signal in the $\alpha 4$ subunit in the assembled $\alpha 4 \beta 2$ receptor complex.

Dendritic targeting signal in the $\alpha 7$ loop mediates selective delivery, whereas axonal targeting signal in the $\alpha 4$ loop mediates fast dendritic endocytosis

One of two general mechanisms may be responsible for the selective localization of polarized proteins on the surface of neurons: selective transport or selective retention. In the first scenario, 

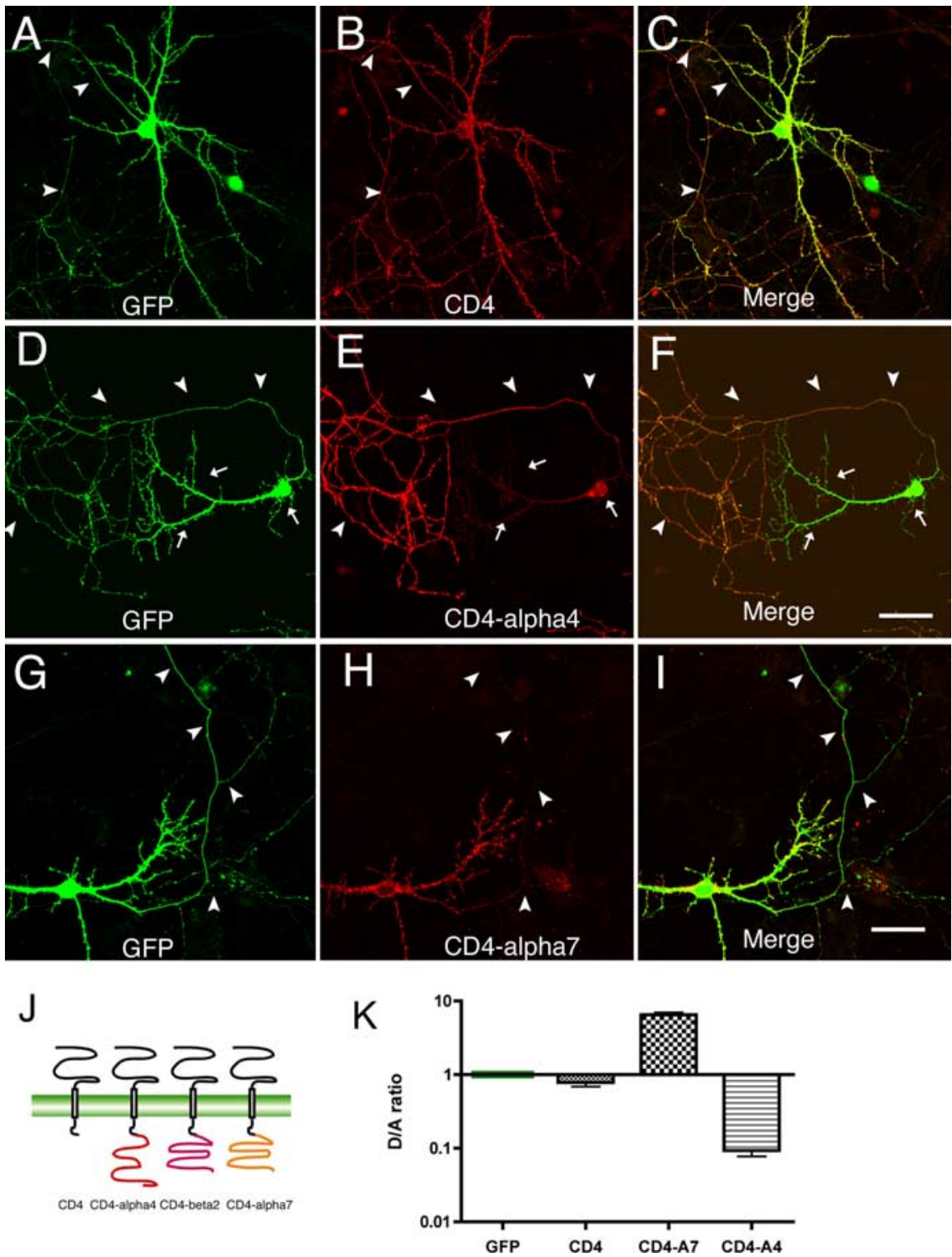

Figure 10. M3-M4 loops from $n A C h R$ subunits confer signals for subcellular targeting. Neurons were transfected at 8 DIV with CD4 (A-C), CD4- $\alpha 4(\boldsymbol{D}-\boldsymbol{F})$, and CD4- $27(\mathbf{G}-\mathbf{I})$ plus GFP. Surface CD4 and CD4 fusion proteins were stained $4 \mathrm{~d}$ later with anti-CD4 antibody. GFP signals (left) labeled axons and dendrites of transfected cells. $A-C$, CD4 surface expression was not polarized. Arrowheads indicate axons. $\boldsymbol{D}-\boldsymbol{F}$, The M3-M4 loop from $\alpha 4$ promoted axonal distribution of fusion protein. Arrows indicate soma-dendrites. G-I, Ubiquitously expressed CD4 became polarized to dendrites after fusion with the M3-M4 loop from $\alpha 7$. Scale bars: (in $\boldsymbol{F}, \boldsymbol{I}) \boldsymbol{A}-\boldsymbol{I}, 40 \mu \mathrm{m} . \boldsymbol{J}$, Schematic representation of CD4 and the CD4/M3-M4 loop fusion proteins. $\boldsymbol{K}$, Normalized D/A ratios of CD4 and the CD4/M3-M4 loop fusion proteins. Error bars are SEM.

proteins destined for either axons or dendrites are segregated from one another into different carriers and only delivered to appropriate subcellular domains. Alternatively, proteins could be delivered equally to axonal and dendritic domains but retained on the surface only in the destined domain.

Quantitative analysis revealed that both surface CD4- $\alpha 7$ $(\mathrm{D} / \mathrm{A}, 6.52 \pm 0.46)$ and total CD4 $-\alpha 7(\mathrm{D} / \mathrm{A}, 6.06 \pm 0.53)$ were expressed primarily in soma-dendrites. This is also consistent with a predominant somatodendritic localization of total $\alpha 7$ receptors (D/A, $12.4 \pm 0.55)$ and surface $\alpha 7$ receptors (D/A, $12.94 \pm 0.68)$. Thus, selective transport to dendrites but not axons is likely to account for dendritic confinement for proteins containing the $\alpha 7$ dendritic targeting motif, as was proposed for dendritic targeting of Kv4.2 potassium channels (Rivera et al., 2003) and TfR-GFP (Silverman et al., 2001).
Interestingly, although surface CD $4-\alpha 4$ was only observed in axons (Fig. $13 A)(\mathrm{D} / \mathrm{A}, 0.09 \pm 0.015)$, total CD $4-\alpha 4$ was found equally in both axons and dendrites (Fig. 13B) (D/A, $0.89 \pm 0.065 ; n=$ 15). This result implies that the $\alpha 4$ axonal signal in CD $4-\alpha 4$ was not used for direct transport to axons; instead, it may be used either to prevent membrane insertion or to rapidly remove $\mathrm{CD} 4-\alpha 4$ from dendritic surface. To distinguish between these two possibilities, we conducted an endocytosis assay to determine whether CD $4-\alpha 4$ was endocytosed from neuronal surface. Briefly, living cells expressing CD $4-\alpha 4$ were first exposed to primary antibody for prolonged periods at $37^{\circ} \mathrm{C}$, followed by the quick stripping of surface-bound receptor. The cells were than fixed, permeabilized, and stained with secondary antibody. Under these conditions, only internalized protein can be visualized. In contrast to the predominant display of surface protein on axons (Fig. 13A) and nonpolarized form for total proteins (Fig. 13B), imaging analysis reveals that the majority of endocytosed signals were restricted to somadendrites, with very little in axons (Fig. $13 C$ ), implying that CD $4-\alpha 4$ was quickly endocytosed from the surface of dendrites, but not axons, after membrane insertion. This result may explain the observed preferential axonal expression of surface CD $4-\alpha 4$ at the steady state. A similar mechanism has been proposed for axonal targeting of $\mathrm{Na}_{\mathrm{V}} 1.2$ (Garrido et al., 2001) and VAMP (vesicle-associated membrane protein) (Sampo et al., 2003).

\section{Discussion}

Our principal findings reported here are, first, that in the hippocampal cultures, $\alpha 7$ and $\alpha 4 \beta 2$ displayed distinct patterns of distribution, with $\alpha 7$ targeted preferentially to the somatodendritic compartments, whereas $\alpha 4 \beta 2$ was expressed at both axonal and dendritic domains. Second, M3-M4 loops from neuronal nAChRs may play key roles in mediating subcellular targeting for these receptors.

Hippocampal culture has been used as an excellent model system to study neuron polarization. Here, we show that this culture system can be applied to identify key sequence elements and conditions that control the distribution of neuronal nAChRs. Unquestionably, receptor distributions in the brain are more complex and likely to vary from different cell types. Nevertheless, our findings agree with results from immunochemical analysis and electrophysiological recordings that $\alpha 7$ receptors are present at somatodendritic compartments in neurons (Alkondon and Albuquerque, 1993; Kawai et al., 2002; Levy and Aoki, 2002). Lacking axonal expression of $\alpha 7$ in hippocampal culture is interesting and unexpected. We cannot rule out the presence of the $\alpha 7$ subunit at specific axons or presynaptic terminals in the brain, as 
other groups have reported (McGehee et al., 1995; Gray et al., 1996; Fabian-Fine et al., 2001; Jones and Wonnacott, 2004). It is possible that axonal expression of $\alpha 7$ requires assembly with another subunit ( $\mathrm{Yu}$ and Role, 1998), was below detection in our experiments, or does not occur in hippocampal cultures. We detected somatodendritic locations of $\alpha 4 \beta 2$. This finding is in agreement with the presence of non- $\alpha 7$ like receptors, possibly $\alpha 4 \beta 2$, in somadendrites of hippocampal neurons (Alkondon et al., 1999; McQuiston and Madison, 1999). The non- $\alpha 7$-like receptors in those hippocampal neurons most likely contain $\alpha 4 \beta 2$ subunits, because they mediate slowly desensitizing responses that are sensitive to the blockade to dihydro- $\beta$-erythroidine and mecamylamine but not to $\alpha$-bungarotoxin or methyllycaconitine (Alkondon et al., 1999; McQuiston and Madison, 1999). We also detected $\alpha 4 \beta 2$ in axons and presynaptic terminals in hippocampal neurons. This observation is consistent with an important role of $\alpha 4 \beta 2$ in modulating transmitter release (Zoli et al., 2002; Champtiaux et al., 2003; Salminen et al., 2004).

It is unlikely that subcellular locations we observed from transfected neurons were caused by overexpression artifact. First, the differential distribution for $\alpha 7$ and $\alpha 4 \beta 2$ subunits is inconsistent with a prediction resulting from overexpression. Second, other membrane proteins that we examined, such as the recombinant glutamate receptor NR1, were expressed at the predicted somatodendritic locations when cotransfected with neuronal nAChRs in cultured neurons (supplemental Fig. 6, available at www.jneurosci.org as supplemental material). Third, we found that the patterns of expression did not vary with different levels of protein expression, which we frequently observed in the transfected neurons. Fourth, we found that sequence motifs from M3-M4 loops of neuronal nAChRs can mediate subcellular targeting in an autonomous manner when fused to normally nonpolarized proteins, consistent with the differential expression that we observed for the nicotinic receptor subunits themselves.

It has been shown previously that some transmembrane proteins are localized in dendrites as a result of direct vesicular transport (Burack et al., 2000). The confinement of total $\alpha 7$ and surface $\alpha 7$ in dendrites but not in axons implies that direct vesicular transport is also responsible for dendritic expression of $\alpha 7$. We observed weak axonal surface expression of $\alpha 7$ at initial regions of axons. This signal may be caused by the diffusion of surface $\alpha 7$ from

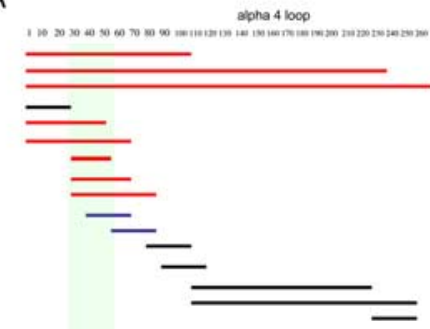

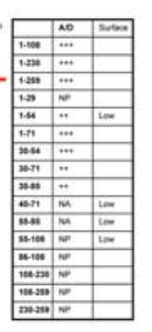

B

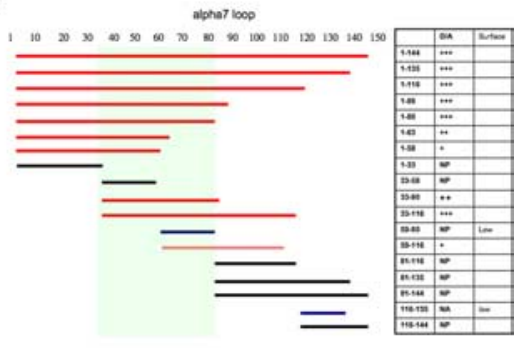

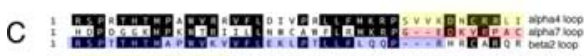
3)

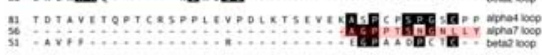

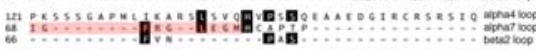

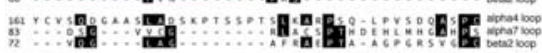

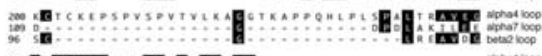

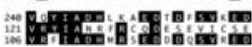

Figure 11. Identification of motifs in M3-M4 loops from the nAChR $\alpha 4$ and $\alpha 7$ subunits that mediate targeted polarization in neurons. $\boldsymbol{A}, \boldsymbol{B}$, Series of C-terminal or N-terminal truncations or internal fragments of M3-M4 loops from $\alpha 4(\boldsymbol{A})$ or $\alpha 7(\boldsymbol{B})$ were fused to IL2RA. Red, black, and blue bars indicate "polarized surface expression," "nonpolarized" (NP), and "not available" (NA), respectively. Relative ratios of polarization for each construct were also represented by + symbols, with +++ representing the most polarized and + representing slightly polarized. Low surface expression was observed from some constructs $(A, B$, right column); for most of these constructs, surface polarization ratios were labeled as NA because of the difficulties in image analysis. C, Sequence alignment of M3-M4 loops from $\alpha 4, \alpha 7$, and $\beta 2$. The axonal sequence in $\alpha 4$ is highlighted in yellow, the dendritic signal of $\alpha 7$ is highlighted in pink, and the first 30 aa from $\beta 2$, which abolishes surface expression, is highlighted in blue. $\boldsymbol{D}$, Identified targeting sequences. Analysis of the surface distribution from fusion proteins defined a 25-residue sequence within $\alpha 4$ loops that governed axonal expression (residues 30-54) and a 48-residue segment from the $\alpha 7$ loop (residues 33-80) that was necessary for dendritic expression. Potential key targeting motifs within the identified segments are underlined, with the consensus motif marked above or below.
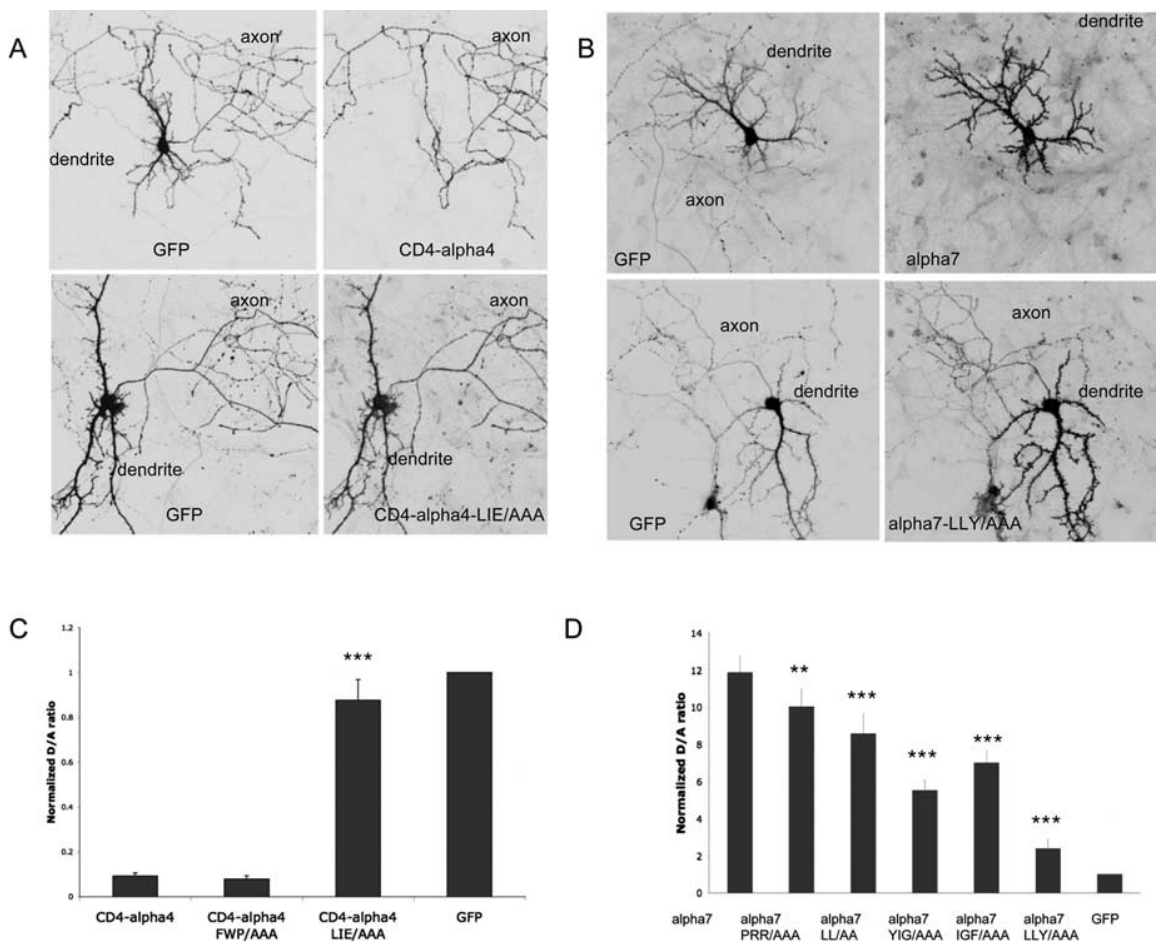

D

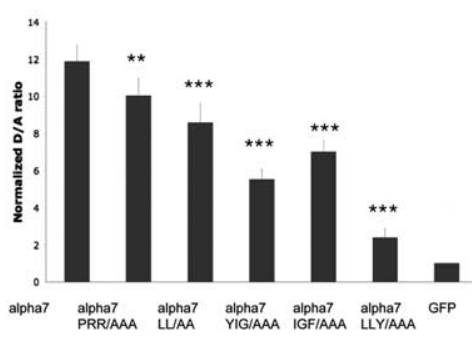

Figure 12. Identifications of key residues within the axonal and dendritic targeting motifs. $A$, Neurons were transfected at 8 DIV with CD4- $\alpha 4$ (top) and CD4- $\alpha 4$-LIE/AAA mutant (bottom) plus GFP (left). GFP signals labeled axons and dendrites of transfected cells. Surface CD4 and CD4 fusion proteins were stained $6 \mathrm{~d}$ later with anti-CD4 antibody (right). Note the absence of signals in soma-dendrites from CD4- $\alpha 4$ but not LIE/AAA mutants. $\boldsymbol{B}$, Neurons were transfected at 8 DIV with $\alpha 7-H A$ (top) and $\alpha 7$-LLY/AAA mutant (bottom) plus GFP (left). Surface receptors were stained $4 \mathrm{~d}$ later with anti-HA antibody (right). Note the absence of axonal signals from wild-type $\alpha 7$ but not LIE/AAA mutant. C, The dendrite/axon ratio of CD4- $\alpha 4$ was affected by the LIE/AAA mutation but not the FWP/AAA mutation. $D$, The dendrite/axon ratio of $\alpha 7$ was affected by mutations introduced in the dileucine and YXX $\phi$ motifs but not by the PRR/AAA mutation. ${ }^{* * *} p<0.001 ;{ }^{* *} p<0.05 ; t$ test. Error bars are SEM. 


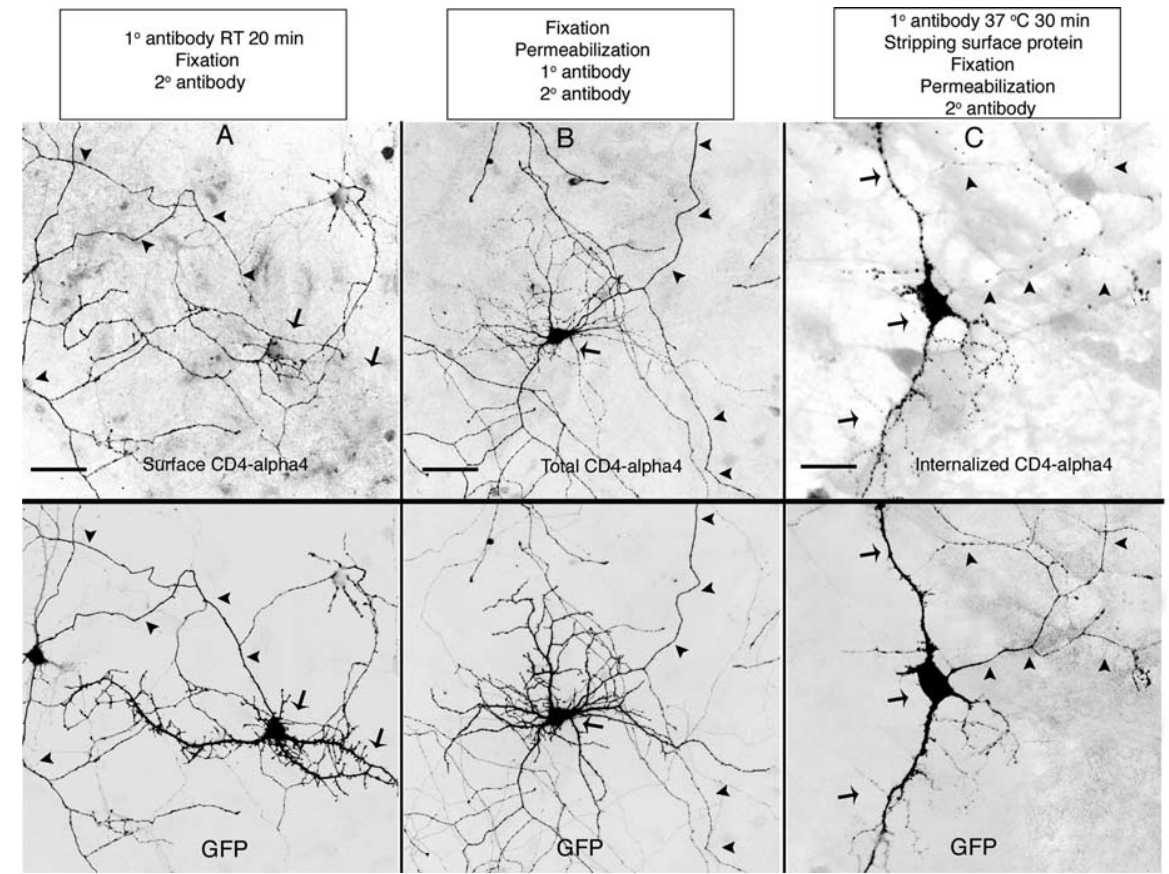

Figure 13. Axonal signal in $\alpha 4$ mediates fast dendritic endocytosis. Sister cultures were studied for surface axonal targeting mediated by $\alpha 4$ axonal sequences. Neurons were transfected with CD4- $\alpha 4$ at 8 DIV. Staining of surface CD4- $\alpha 4(\boldsymbol{A})$, total CD4 $-\alpha 4(\boldsymbol{B})$, and endocytosed CD4 $-\alpha 4(\boldsymbol{C})$ was performed at 12 DIV. Surface CD4 $-\alpha 4$ was primarily found in axons $(\boldsymbol{A} ; \mathrm{D} / \mathrm{A}$, $0.09 \pm 0.015)$, whereas total CD4 $-\alpha 4$ was found equally in both axons and dendrites $(\boldsymbol{B} ; \mathrm{D} / \mathrm{A}, 0.89 \pm 0.65 ; n=15)$. Endocytosis assay was performed by first exposing the cells to primary antibody for $30 \mathrm{~min}$ at $37^{\circ} \mathrm{C}$, followed by the quick stripping of surface-bound receptor. The cells were then fixed, permeabilized, and stained with secondary antibody. Under these conditions, only internalized proteins were visualized. In contrast to the predominant display of surface protein on axons $(\boldsymbol{A})$ and nonpolarized form for total protein $(\boldsymbol{B})$, the majority of endocytosed signals were found in soma-dendrites with little in axons (C). Arrows indicate soma-dendrites. Arrowheads indicate axons. Scale bars, $50 \mu \mathrm{m}$.

dendrites. However, the presence of a diffusion barrier (Kobayashi et al., 1992; Winckler et al., 1999) at the axonal hillock/ initial segment may prohibit these proteins from advancing farther into axons. Although the exact location of such a barrier is not known, Winckler et al. (1999) suggested that the barrier might be situated at the initial segment instead of the hillock. They found that GluR1, a dendritic AMPA receptor, extended $\sim 33 \mu \mathrm{m}$ beyond the axon hillock ( $\sim 50 \mu \mathrm{m}$ from the cell body, assuming the axon hillock to be $\sim 20 \mu \mathrm{m})$. This measurement is comparable with the distance we estimated for $\alpha 7(\lambda=47 \mu \mathrm{m})$. Interestingly, weak axonal staining at the initial segment was also seen from several other dendritic-targeted proteins, such as EAAT3 (excitatory amino acid transporter 3) (Cheng et al., 2002) and TfR-GFP (Burack et al., 2000; Silverman et al., 2001). These observations suggest that the occurrence of dendritic proteins at the initial region of the axon might be a common phenomenon that is in agreement with the existence of a diffusion barrier within the initial segment of axons.

The mechanism accounting for the distribution of $\alpha 4 \beta 2$ in hippocampal neurons is more problematical to understand. This is, at least to some extent, attributable to the complexity of receptor heteromerization, another important but poorly understood aspect of neuronal nAChRs. What is really intriguing is that the axonal targeting motif found in the $\alpha 4$ loop was capable of constraining surface expression of nonpolarized proteins, such as CD4 and IL2RA, to axons, but the same signal was ineffectual for axonal targeting of the $\alpha 4 \beta 2$ complex. One explanation is that the $\alpha 4$ axonal signal was masked in the assembled $\alpha 4 \beta 2$ complex but was exposed in CD $4-\alpha 4$ and IL2RA- $\alpha 4$ proteins. A previous report that an ER retention signal is buried in assembled muscle nAChRs but is exposed on unassembled subunits suggests that such a hypothesis is plausible (Wang et al., 2002). Consistent with this hypothesis, mutating key residues within the axonal motif in the $\alpha 4$ subunit did not lead to a significant change of dendrite/axon ratio. Whether or not this axonal targeting signal is exposed when $\alpha 4$ subunits assemble with other subunits remains to be determined. It is also possible that this axonal targeting signal could be reexposed when the $\alpha 4 \beta 2$ receptor undergoes conformational changes, such as transitions between opening, closed, and desensitization stages. Provided that the axonal targeting motif in $\alpha 4$ operates by facilitating fast dendritic endocytosis (Fig. 13C), a fine control of its conformational or functional state may provide an additional mechanism for neurons to upregulate or downregulate surface receptors in dendrites.

The amino acid sequence of the long cytosolic M3-M4 loop is highly divergent among all of the nAChR subunits (Le Novere et al., 1999). What are the roles of these M3-M4 loops in the biogenesis of nAChRs? Previous studies indicate that residues within M3-M4 loops are involved in receptor assembly ( $\mathrm{Yu}$ and Hall, 1994), ER export (Ren et al., 2005), and the ubiquitin-proteosome pathway (Ficklin et al., 2005). It has also been demonstrated that the M3-M4 loop from the chick $\alpha 3$ subunit targets this receptor to subdomains within individual synapses on developing CG neurons (Williams et al., 1998; Temburni et al., 2000). Here, we show that M3-M4 loops from mammalian neuronal nAChRs are involved in axon/dendrite distribution. These results further underscore the diverse functions of these cytoplasmic loops. We fully expect future studies of these loops from other neuronal $\mathrm{nAChRs}$ to lead to a better understanding of receptor targeting in neurons.

In the past several years, progress has been made in identifying axonal and dendritic targeting motifs for voltage-gated ion channels (Garrido et al., 2001, 2003; Gu et al., 2003; Rivera et al., 2003). Sequence requirements for the subcellular targeting of ligand-gated receptors are less clear. Although several motifs have been identified, such as the C-terminal domains from the metabotropic glutamate receptors (Stowell and Craig, 1999) and AMPA receptors (Ruberti and Dotti, 2000), the required amino acids have not been mapped precisely. Here, we identified a $25-$ residue axonal targeting sequence that contains the dileucine motif ([DE]XXXL[LI]) and a 48-residue dendritic targeting sequence enclosing the dileucine and tyrosine (YXXØ) motifs. These findings contribute to an understanding of the subcellular distribution of neuronal nAChRs and perhaps other neuronal membrane proteins. The exact mechanism by which these targeting motifs mediate neuronal targeting of nAChRs is unknown. Both tyrosine-based and dileucine-containing signals have been found to bind to subunits of adaptor protein complexes (Ohno et al., 1995; Rapoport et al., 1998). It is possible that the interactions of such adaptors with the targeting motifs that we have identified 
may either facilitate clathrin-mediated endocytosis of the existing receptors or contribute to the loading of newly synthesized receptors into vesicles bound for specific locations (Burack et al., 2000; Garrido et al., 2001; Bonifacino and Traub, 2003).

In conclusion, our results demonstrate distinct targeting patterns for different neuronal nAChRs that depend on critical sequence elements in the intracellular domains of the nAChR subunits. We found that both $\alpha 7$-containing and $\alpha 4 \beta 2$-containing receptors were expressed at soma and mature spines in cultures of primary neurons. We also found that $\alpha 4 \beta 2$-containing receptors were expressed to axons and presynaptic terminals in these neurons. These findings have implications for the roles of neuronal $\mathrm{nAChRs}$ in synaptic transmission and in nicotine-induced behaviors.

\section{References}

Alkondon M, Albuquerque EX (1993) Diversity of nicotinic acetylcholine receptors in rat hippocampal neurons. I. Pharmacological and functional evidence for distinct structural subtypes. J Pharmacol Exp Ther 265:1455-1473.

Alkondon M, Pereira EF, Barbosa CT, Albuquerque EX (1997) Neuronal nicotinic acetylcholine receptor activation modulates gammaaminobutyric acid release from CA1 neurons of rat hippocampal slices. J Pharmacol Exp Ther 283:1396-1411.

Alkondon M, Pereira EF, Eisenberg HM, Albuquerque EX (1999) Choline and selective antagonists identify two subtypes of nicotinic acetylcholine receptors that modulate GABA release from CA1 interneurons in rat hippocampal slices. J Neurosci 19:2693-2705.

Alkondon M, Pereira EF, Almeida LE, Randall WR, Albuquerque EX (2000) Nicotine at concentrations found in cigarette smokers activates and desensitizes nicotinic acetylcholine receptors in CA1 interneurons of rat hippocampus. Neuropharmacology 39:2726-2739.

Arroyo-Jiménez MM, Bourgeois JP, Marubio LM, Le Sourd AM, Ottersen OP, Rinvik E, Fairen A, Changeux JP (1999) Ultrastructural localization of the $\alpha 4$-subunit of the neuronal acetylcholine nicotinic receptor in the rat substantia nigra. J Neurosci 19:6475-6487.

Bonifacino JS, Traub LM (2003) Signals for sorting of transmembrane proteins to endosomes and lysosomes. Annu Rev Biochem 72:395-447.

Boyer C, Schikorski T, Stevens CF (1998) Comparison of hippocampal dendritic spines in culture and in brain. J Neurosci 18:5294-5300.

Burack MA, Silverman MA, Banker G (2000) The role of selective transport in neuronal protein sorting. Neuron 26:465-472.

Callahan CA, Yoshikawa S, Thomas JB (1998) Tracing axons. Curr Opin Neurobiol 8:582-586

Champtiaux N, Gotti C, Cordero-Erausquin M, David DJ, Przybylski C, Lena C, Clementi F, Moretti M, Rossi FM, Le Novere N, McIntosh JM, Gardier AM, Changeux JP (2003) Subunit composition of functional nicotinic receptors in dopaminergic neurons investigated with knock-out mice. J Neurosci 23:7820-7829.

Cheng C, Glover G, Banker G, Amara SG (2002) A novel sorting motif in the glutamate transporter excitatory amino acid transporter 3 directs its targeting in Madin-Darby canine kidney cells and hippocampal neurons. J Neurosci 22:10643-10652.

Corringer PJ, Le Novere N, Changeux JP (2000) Nicotinic receptors at the amino acid level. Annu Rev Pharmacol Toxicol 40:431-458.

Couturier S, Bertrand D, Matter JM, Hernandez MC, Bertrand S, Millar N, Valera S, Barkas T, Ballivet M (1990) A neuronal nicotinic acetylcholine receptor subunit (alpha 7) is developmentally regulated and forms a homo-oligomeric channel blocked by alpha-BTX. Neuron 5:847-856.

Craig AM, Banker G (1994) Neuronal polarity. Annu Rev Neurosci 17:267-310.

Dajas-Bailador F, Wonnacott S (2004) Nicotinic acetylcholine receptors and the regulation of neuronal signalling. Trends Pharmacol Sci 25:317-324.

Dani JA, Heinemann S (1996) Molecular and cellular aspects of nicotine abuse. Neuron 16:905-908.

Dotti CG, Sullivan CA, Banker GA (1988) The establishment of polarity by hippocampal neurons in culture. J Neurosci 8:1454-1468.

Fabian-Fine R, Skehel P, Errington ML, Davies HA, Sher E, Stewart MG, Fine
A (2001) Ultrastructural distribution of the $\alpha 7$ nicotinic acetylcholine receptor subunit in rat hippocampus. J Neurosci 21:7993-8003.

Ficklin MB, Zhao S, Feng G (2005) Ubiquilin-1 regulates nicotine-induced up-regulation of neuronal nicotinic acetylcholine receptors. J Biol Chem 280:34088-34095.

Frazier CJ, Rollins YD, Breese CR, Leonard S, Freedman R, Dunwiddie TV (1998a) Acetylcholine activates an $\alpha$-bungarotoxin-sensitive nicotinic current in rat hippocampal interneurons, but not pyramidal cells. J Neurosci 18:1187-1195.

Frazier CJ, Buhler AV, Weiner JL, Dunwiddie TV (1998b) Synaptic potentials mediated via $\alpha$-bungarotoxin-sensitive nicotinic acetylcholine receptors in rat hippocampal interneurons. J Neurosci 18:8228-8235.

Garrido JJ, Fernandes F, Giraud P, Mouret I, Pasqualini E, Fache MP, Jullien F, Dargent B (2001) Identification of an axonal determinant in the C-terminus of the sodium channel Na(v)1.2. EMBO J 20:5950-5961.

Garrido JJ, Giraud P, Carlier E, Fernandes F, Moussif A, Fache MP, Debanne D, Dargent B (2003) A targeting motif involved in sodium channel clustering at the axonal initial segment. Science 300:2091-2094.

Gray R, Rajan AS, Radcliffe KA, Yakehiro M, Dani JA (1996) Hippocampal synaptic transmission enhanced by low concentrations of nicotine. Nature 383:713-716.

Gu C, Jan YN, Jan LY (2003) A conserved domain in axonal targeting of Kv1 (Shaker) voltage-gated potassium channels. Science 301:646-649.

Hefft S, Hulo S, Bertrand D, Muller D (1999) Synaptic transmission at nicotinic acetylcholine receptors in rat hippocampal organotypic cultures and slices. J Physiol (Lond) 515:769-776.

Herber DL, Severance EG, Cuevas J, Morgan D, Gordon MN (2004) Biochemical and histochemical evidence of nonspecific binding of alpha7nAChR antibodies to mouse brain tissue. J Histochem Cytochem 52:1367-1376.

Hering H, Sheng M (2001) Dendritic spines: structure, dynamics and regulation. Nat Rev Neurosci 2:880-888.

Horton AC, Ehlers MD (2003) Neuronal polarity and trafficking. Neuron 40:277-295.

Ji D, Lape R, Dani JA (2001) Timing and location of nicotinic activity enhances or depresses hippocampal synaptic plasticity. Neuron 31:131-141.

Jones IW, Wonnacott S (2004) Precise localization of $\alpha 7$ nicotinic acetylcholine receptors on glutamatergic axon terminals in the rat ventral tegmental area. J Neurosci 24:11244-11252.

Jones IW, Bolam JP, Wonnacott S (2001) Presynaptic localisation of the nicotinic acetylcholine receptor beta2 subunit immunoreactivity in rat nigrostriatal dopaminergic neurones. J Comp Neurol 439:235-247.

Jones S, Yakel JL (1997) Functional nicotinic ACh receptors on interneurones in the rat hippocampus. J Physiol (Lond) 504:603-610.

Kawai H, Zago W, Berg DK (2002) Nicotinic $\alpha 7$ receptor clusters on hippocampal GABAergic neurons: regulation by synaptic activity and neurotrophins. J Neurosci 22:7903-7912.

Khiroug L, Giniatullin R, Klein RC, Fayuk D, Yakel JL (2003) Functional mapping and $\mathrm{Ca}^{2+}$ regulation of nicotinic acetylcholine receptor channels in rat hippocampal CA1 neurons. J Neurosci 23:9024-9031.

Kobayashi T, Storrie B, Simons K, Dotti CG (1992) A functional barrier to movement of lipids in polarized neurons. Nature 359:647-650.

Le Novere N, Corringer PJ, Changeux JP (1999) Improved secondary structure predictions for a nicotinic receptor subunit: incorporation of solvent accessibility and experimental data into a two-dimensional representation. Biophys J 76:2329-2345.

Levy RB, Aoki C (2002) $\alpha 7$ nicotinic acetylcholine receptors occur at postsynaptic densities of AMPA receptor-positive and -negative excitatory synapses in rat sensory cortex. J Neurosci 22:5001-5015.

Liu Y, Ford B, Mann MA, Fischbach GD (2001) Neuregulins increase $\alpha 7$ nicotinic acetylcholine receptors and enhance excitatory synaptic transmission in GABAergic interneurons of the hippocampus. J Neurosci 21:5660-5669.

Lukas RJ, Changeux JP, Le Novere N, Albuquerque EX, Balfour DJ, Berg DK, Bertrand D, Chiappinelli VA, Clarke PB, Collins AC, Dani JA, Grady SR, Kellar KJ, Lindstrom JM, Marks MJ, Quik M, Taylor PW, Wonnacott S (1999) International Union of Pharmacology. XX. Current status of the nomenclature for nicotinic acetylcholine receptors and their subunits. Pharmacol Rev 51:397-401.

Mansvelder HD, McGehee DS (2000) Long-term potentiation of excitatory inputs to brain reward areas by nicotine. Neuron 27:349-357.

McGehee DS, Heath MJ, Gelber S, Devay P, Role LW (1995) Nicotine en- 
hancement of fast excitatory synaptic transmission in CNS by presynaptic receptors. Science 269:1692-1696.

McQuiston AR, Madison DV (1999) Nicotinic receptor activation excites distinct subtypes of interneurons in the rat hippocampus. J Neurosci 19:2887-2896.

Nashmi R, Dickinson ME, McKinney S, Jareb M, Labarca C, Fraser SE, Lester HA (2003) Assembly of $\alpha 4 \beta 2$ nicotinic acetylcholine receptors assessed with functional fluorescently labeled subunits: effects of localization, trafficking, and nicotine-induced upregulation in clonal mammalian cells and in cultured midbrain neurons. J Neurosci 23:11554-11567.

Ohno H, Stewart J, Fournier MC, Bosshart H, Rhee I, Miyatake S, Saito T, Gallusser A, Kirchhausen T, Bonifacino JS (1995) Interaction of tyrosine-based sorting signals with clathrin-associated proteins. Science 269:1872-1875.

Papa M, Bundman MC, Greenberger V, Segal M (1995) Morphological analysis of dendritic spine development in primary cultures of hippocampal neurons. J Neurosci 15:1-11.

Rao A, Kim E, Sheng M, Craig AM (1998) Heterogeneity in the molecular composition of excitatory postsynaptic sites during development of hippocampal neurons in culture. J Neurosci 18:1217-1229.

Rapoport I, Chen YC, Cupers P, Shoelson SE, Kirchhausen T (1998) Dileucine-based sorting signals bind to the beta chain of AP-1 at a site distinct and regulated differently from the tyrosine-based motif-binding site. EMBO J 17:2148-2155.

Ren XQ, Cheng SB, Treuil MW, Mukherjee J, Rao J, Braunewell KH, Lindstrom JM, Anand R (2005) Structural determinants of $\alpha 4 \beta 2$ nicotinic acetylcholine receptor trafficking. J Neurosci 25:6676-6686.

Rivera JF, Ahmad S, Quick MW, Liman ER, Arnold DB (2003) An evolutionarily conserved dileucine motif in Shal $\mathrm{K}+$ channels mediates dendritic targeting. Nat Neurosci 6:243-250.

Role LW, Berg DK (1996) Nicotinic receptors in the development and modulation of CNS synapses. Neuron 16:1077-1085.

Ruberti F, Dotti CG (2000) Involvement of the proximal C terminus of the AMPA receptor subunit GluR1 in dendritic sorting. J Neurosci 20:RC78(1-5).

Salminen O, Murphy KL, McIntosh JM, Drago J, Marks MJ, Collins AC, Grady SR (2004) Subunit composition and pharmacology of two classes of striatal presynaptic nicotinic acetylcholine receptors mediating dopamine release in mice. Mol Pharmacol 65:1526-1535.
Sampo B, Kaech S, Kunz S, Banker G (2003) Two distinct mechanisms target membrane proteins to the axonal surface. Neuron 37:611-624.

Sargent PB (1993) The diversity of neuronal nicotinic acetylcholine receptors. Annu Rev Neurosci 16:403-443.

Silverman MA, Kaech S, Jareb M, Burack MA, Vogt L, Sonderegger P, Banker G (2001) Sorting and directed transport of membrane proteins during development of hippocampal neurons in culture. Proc Natl Acad Sci USA 98:7051-7057.

Stowell JN, Craig AM (1999) Axon/dendrite targeting of metabotropic glutamate receptors by their cytoplasmic carboxy-terminal domains. Neuron 22:525-536.

Temburni MK, Blitzblau RC, Jacob MH (2000) Receptor targeting and heterogeneity at interneuronal nicotinic cholinergic synapses in vivo. J Physiol (Lond) 525:21-29.

Wang JM, Zhang L, Yao Y, Viroonchatapan N, Rothe E, Wang ZZ (2002) A transmembrane motif governs the surface trafficking of nicotinic acetylcholine receptors. Nat Neurosci 5:963-970.

Williams BM, Temburni MK, Levey MS, Bertrand S, Bertrand D, Jacob MH (1998) The long internal loop of the alpha 3 subunit targets nAChRs to subdomains within individual synapses on neurons in vivo. Nat Neurosci $1: 557-562$.

Winckler B, Forscher P, Mellman I (1999) A diffusion barrier maintains distribution of membrane proteins in polarized neurons. Nature 397:698-701.

Wonnacott S (1997) Presynaptic nicotinic ACh receptors. Trends Neurosci 20:92-98.

Yu CR, Role LW (1998) Functional contribution of the alpha5 subunit to neuronal nicotinic channels expressed by chick sympathetic ganglion neurones. J Physiol (Lond) 509:667-681.

Yu XM, Hall ZW (1994) A sequence in the main cytoplasmic loop of the alpha subunit is required for assembly of mouse muscle nicotinic acetylcholine receptor. Neuron 13:247-255.

Zarei MM, Radcliffe KA, Chen D, Patrick JW, Dani JA (1999) Distributions of nicotinic acetylcholine receptor alpha7 and beta2 subunits on cultured hippocampal neurons. Neuroscience 88:755-764.

Zoli M, Moretti M, Zanardi A, McIntosh JM, Clementi F, Gotti C (2002) Identification of the nicotinic receptor subtypes expressed on dopaminergic terminals in the rat striatum. J Neurosci 22:8785-8789. 